\title{
A hierarchical finite element for composite laminated beams using a refined zigzag theory
}

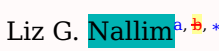

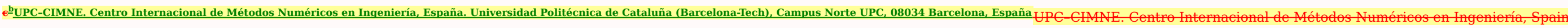

dUniversidad Politécnica do Cataluña (Barcelona Tech), Spain

${ }^{\mathrm{e}} \mathrm{IDIT}$ - Departamento de Estructuras, Universidad Nacional de Córdoba and CONICET, Av. Velez Sarsfield 1611, 5016 Córdoba, Argentina

${ }^{*}$ Corresponding author at: INIQUI-CONICET.Facultad de Ingeniería, Universidad Nacional de Salta, Av. Bolivia 5150, 4400 Salta-Consejo Nacional de Investigaciones Científieas y Téenicas, Argentina.

\section{Abstract}

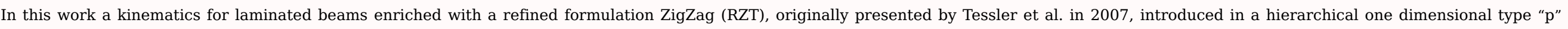

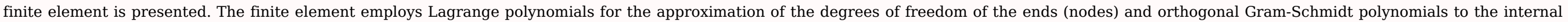

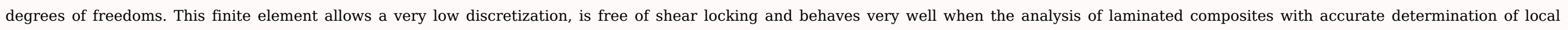
stresses and strains at laminar level is necessary.

This element has been validated in the analysis of laminated beams with various sequences of symmetric and asymmetric stacking, studying in each case its accuracy and stability. Kevwords:

Refined zigzag theory; Hierarchical finite element method; PRZ element; Beam finite element; Composite beam; Laminated beam

\section{Introduction and review}

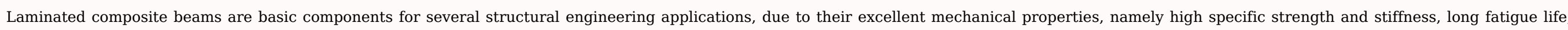

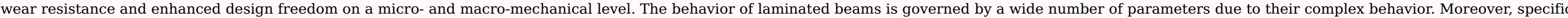

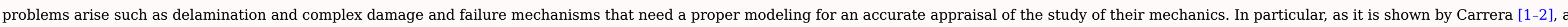

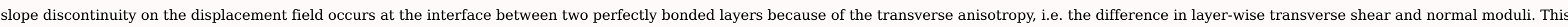
is known as the ZigZag (ZZ) phenomenon.

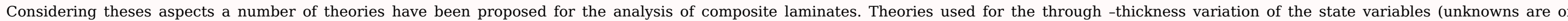

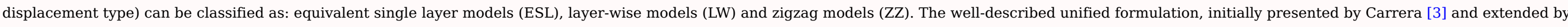
Demasi [4-8], describes precisely and clearly the models, types and class of these theories.-

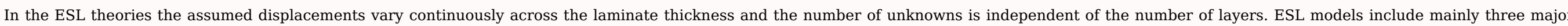




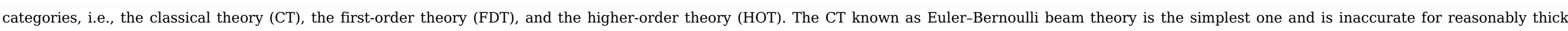

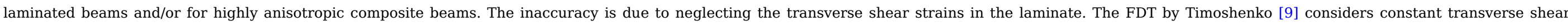

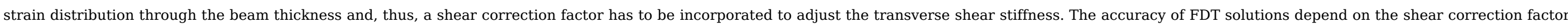

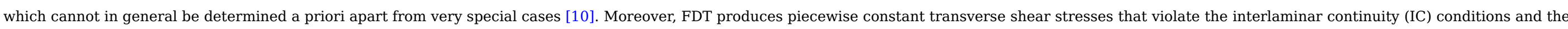

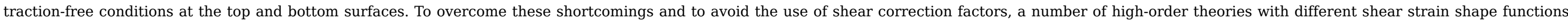

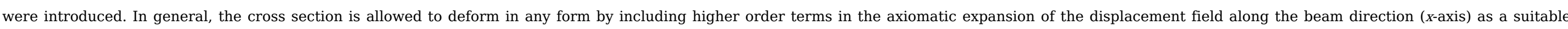

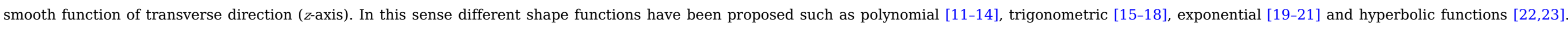

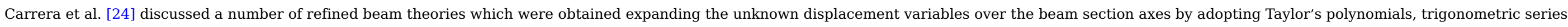

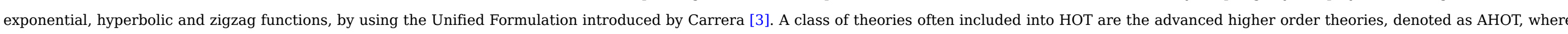

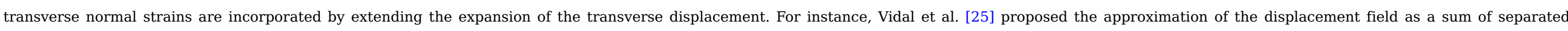

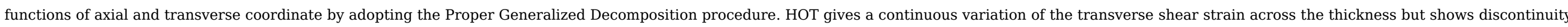

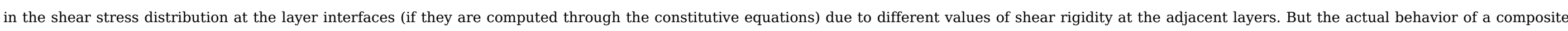
laminate is opposite i.e., the transverse shear stress must be continuous at the layer interface and the corresponding strain may be discontinuous [26].

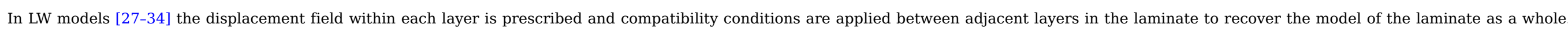

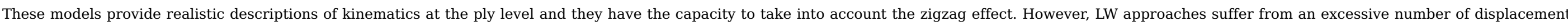
variables in proportion to the number of layers and hence they are too expensive in terms of computational cost and hardly appropriate for practical applications.

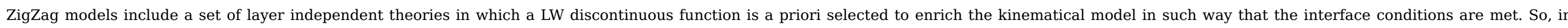

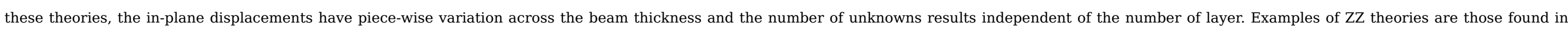
articles published by Murakami [35], Lee et al. [36], Cho and Paramerter [37], Cho and Averill [38], Vidal and Polit [39,40].

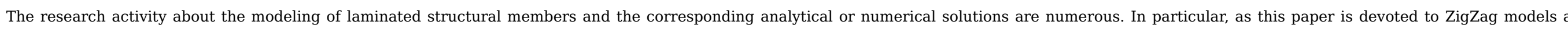

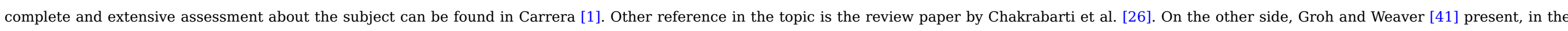
article introduction, a comprehensive overview of the different theories that are used for the analysis of highly heterogeneous laminated beams.

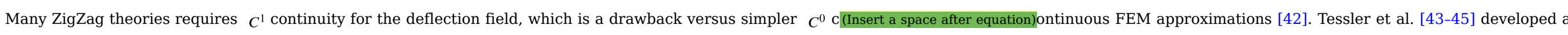

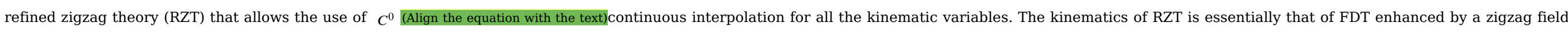
which has the property of vanishing on the top and bottom surface of the laminate.

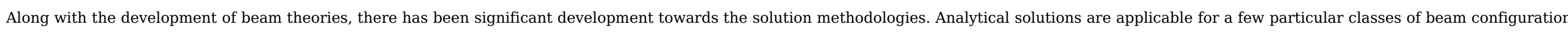

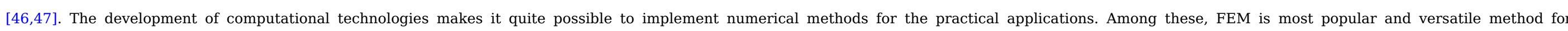

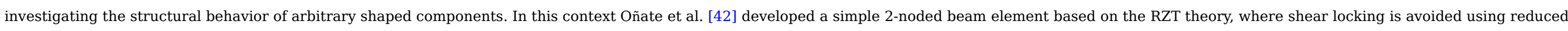

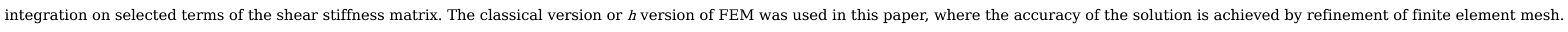

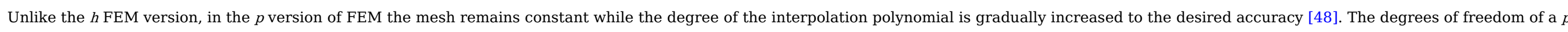

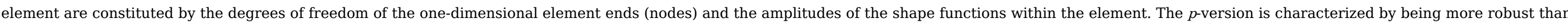

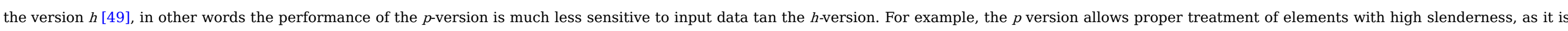

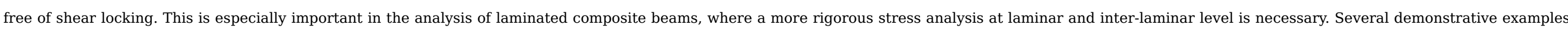

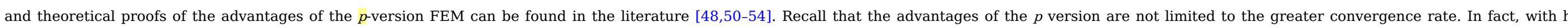

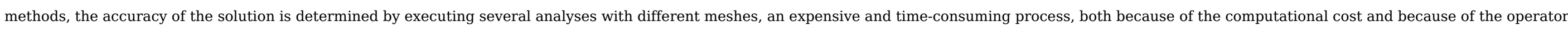
time required to define the different models. In p-convergent approximations, the number of finite elements is determined by the geometry and is small [55]. 


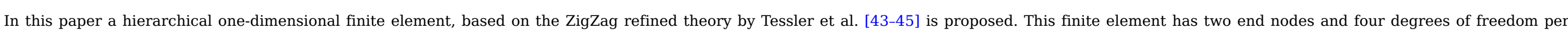

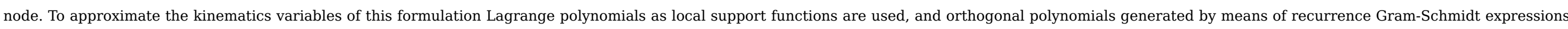

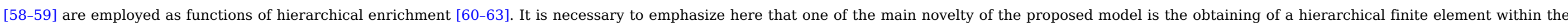

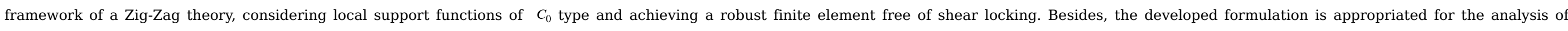

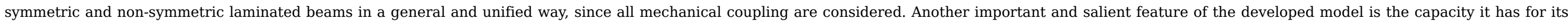
application to the delamination study as will be seen in Section 8.

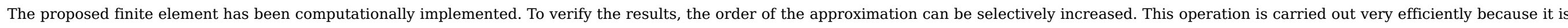

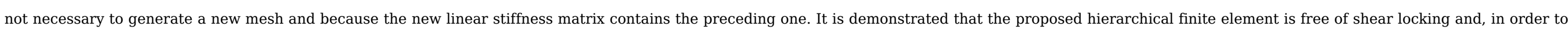
assess its accuracy and stability, it has been applied to the analysis of laminated beams with symmetrical and non-symmetrical stacking sequence with different boundary conditions.

\section{Formulation of the mechanical problem}

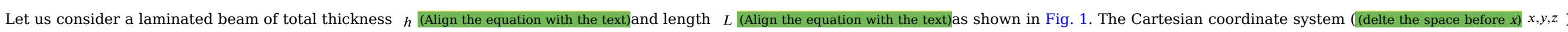

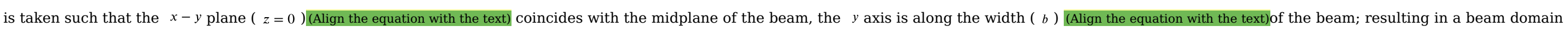

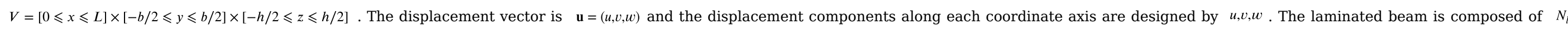

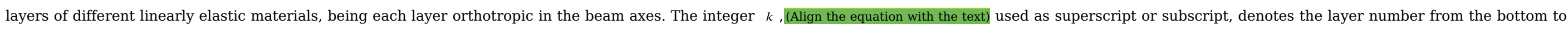
the top of the beam; thus the $k t h$ (Align the equation with the text)layer corresponds to $z_{k-1} \leqslant z \leqslant z_{k}$ and its thickness is $h_{k}$.

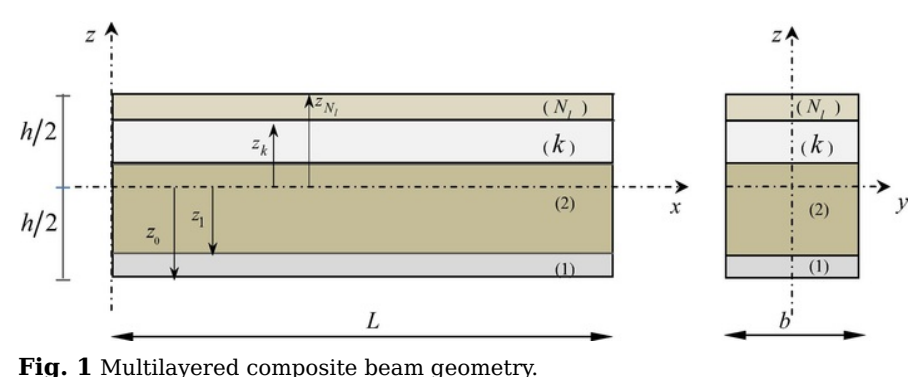

Fig. 1 Multilayered composite beam geometry.

The one dimensional constitutive equations of the $k$ th layer of an orthotropic material are given by

$$
\left[\begin{array}{l}
\sigma_{x x} \\
\tau_{x z}
\end{array}\right]^{(k)}=\left[\begin{array}{ll}
\bar{C}_{11} & 0 \\
0 & \bar{C}_{55}
\end{array}\right]^{(k)}\left[\begin{array}{l}
\varepsilon_{x x} \\
\gamma_{x z}
\end{array}\right]^{(k)} \text {, i.e. } \quad \boldsymbol{\sigma}^{(k)}=\overline{\mathbf{C}}^{(k)} \boldsymbol{\varepsilon}^{(k)}
$$

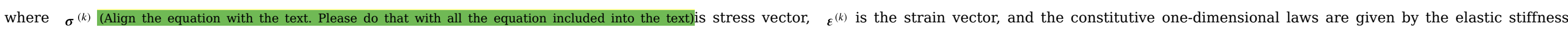
matrix $\overline{\mathbf{C}}^{(k)}$ for the kth layer.

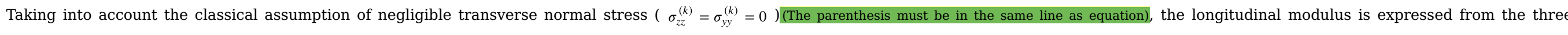
dimensional constitutive laws by

$\bar{C}_{11}^{(k)}=C_{11}^{(k)}-2\left(C_{12}^{(k)}\right)^{2} /\left(C_{23}^{(k)}+C_{33}^{(k)}\right)$

where $C_{i j}$ are orthotropic three-dimensional elastic moduli [56].

The transverse shear stress modulus is given by $\bar{C}_{55}^{(k)}=C_{55}^{(k)}=G_{x z}^{(k)}$ 
The general weak form of the boundary value problem for the beam shown in Fig. 1, considering Eq. (1) and a virtual displacement vector $\delta \mathbf{u}$, is given by the classical virtual work expression $\int_{V}\left(\delta \boldsymbol{\varepsilon}^{(k)}\right)^{T} \boldsymbol{\sigma}^{(k)}(\mathbf{u}) d V-\int_{V}(\delta \mathbf{u})^{T} \mathbf{g} d V-\int_{\partial V_{F}}(\delta \mathbf{u})^{T} \mathbf{F} d \partial V=0$

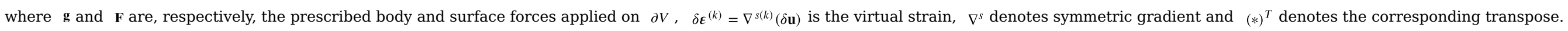

Substituting Eq. (1) into the weak form of the boundary value problem, Eq. (4) results:

$\int_{V}\left(\delta \boldsymbol{\varepsilon}^{(k)}\right)^{T} \overline{\mathbf{C}}^{(k)} \boldsymbol{\varepsilon}^{(k)} d V-\int_{V}(\delta \mathbf{u})^{T} \mathbf{g} d V-\int_{\partial V_{F}}(\delta \mathbf{u})^{T} \mathbf{F} d \partial V=0$

Eq. (5) will be used in Section 4 as the starting point for the proposed hierarchical finite element approximations.

\section{Bases of the refined zigzag theory}

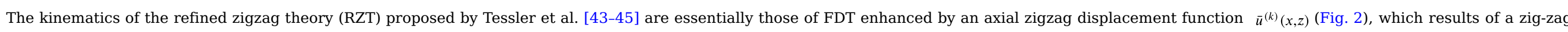
field $\psi(x)$ multiplied by a piecewise continuous transverse function $\phi^{(k)}(z)$, as follows

\begin{tabular}{|c|c|}
\hline$u^{(k)}(x, z)=u_{0}(x)-z \frac{d \theta(x)}{d x}+\bar{u}^{(k)}(x, z)$ & $u^{(k)}(x, z)=u_{0}(x)-z \theta(x)+\bar{u}^{(k)}(x, z)$ \\
$w(x, z)=w_{0}(x)$ & $w(x, z)=w_{0}(x)$ \\
\hline
\end{tabular}

where

$\bar{u}^{(k)}(x, z)=\phi^{(k)}(z) \psi(x)$

(a)

Zigzag function

$z \dot{\Lambda}$

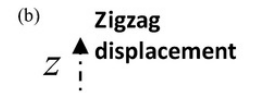
$z \underset{i}{\mathbf{i}}$ displacement

$k=3$

$\zeta^{(2)}$
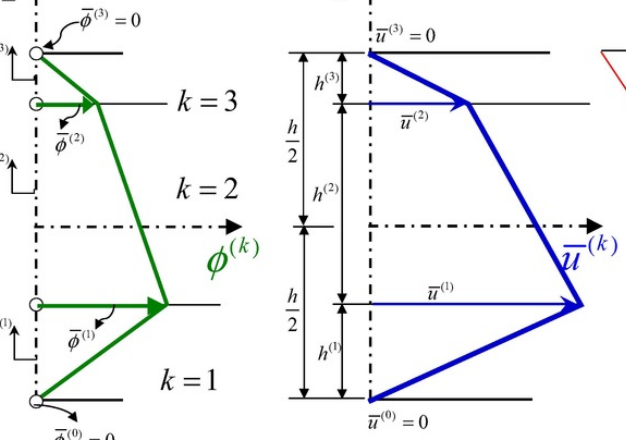

(c) Axial

$z$ Aisplacement

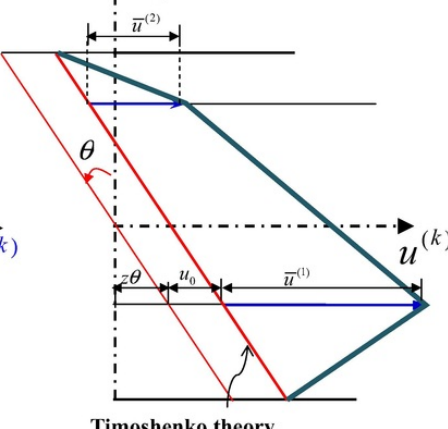

Timoshenko theory

Fig. 2 Schematic representation of the RZT. Thickness distribution of: (a) zigzag function, (b) zigzag displacement, and (c) axial displacement.

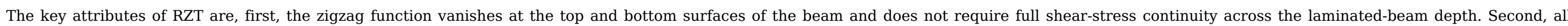

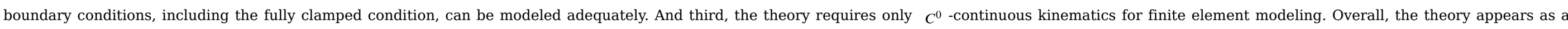
natural extension of Timoshenko theory to laminated composite beams.

Within each layer the zigzag function, depicted in Fig. 1(a), is expressed as

$\phi^{(k)}=\frac{1}{2}\left(1-\zeta^{(k)}\right) \bar{\phi}^{(k-1)}+\frac{1}{2}\left(1+\zeta^{(k)}\right) \bar{\phi}^{(k)}$

where $\bar{\phi}^{(k-1)}$ and $\bar{\phi}^{(k)}$ are the zigzag function values of $(k-1)$ and $(k)$ interfaces respectively, being $\bar{\phi}^{(0)}=\bar{\phi}^{\left(N_{l}\right)}=0$, and $\zeta^{(k)}=2\left(z-z^{(k-1)}\right) / h^{(k)}-1$.

The zigzag slope $d \phi^{(k)} / d z$, is denoted by $\beta^{(k)}$ and it is computed from Eq. (8) as 
In this theory the zigzag slope $\beta^{(k)}$ is defined by the difference between the transverse shear rigidity of a layer $G_{x z}^{(k)}$, and the effective transverse shear rigidity $G$ of the entire layup, $\beta^{(k)}=\frac{G}{G_{x z}^{(k)}}-1$

being

$G=A\left[\iint_{A} \frac{d A}{G_{x z}^{(k)}}\right]^{-1}=h\left[\sum_{k=1}^{N_{l}} \frac{h^{(k)}}{G_{x z}^{(k)}}\right]^{-1}$

Introducing Eqs. (9) and (10) into Eq. (8) the expression for the zigzag function for the RZT is obtained,

$\bar{\phi}^{(k)}=\beta^{(k)} h^{(k)}+\bar{\phi}^{(k-1)} \quad$ and $\quad \phi^{(k)}=\frac{h^{(k)} \beta^{(k)}}{2}\left(\zeta^{(k)}-1\right)+\sum_{i=1}^{k} h^{(i)} \beta^{(i)}$

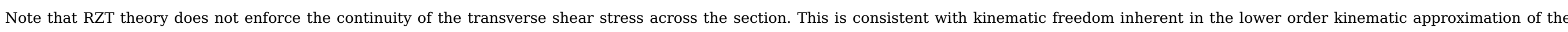
underlying beam theory. The reader can obtain a more detailed description of the RZT in Tessler et al. [43-45] and Oñate et al. [42].

\section{Hierarchical finite beam element for the refined zigzag theory}

\subsection{Shape functions}

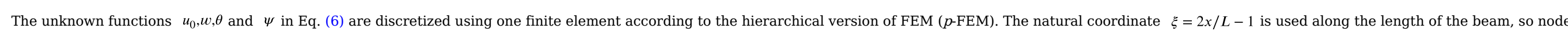
1 corresponds to $\xi=-1(x=0)$ and node 2 corresponds to $\xi=1(x=L)$. The proposed one - dimensional approximation is given by

$\left(u_{0}, w, \theta, \psi\right)=\sum_{i=1}^{n_{u}, n_{w}, n_{\theta}, n_{\psi}} N_{i}(\xi)\left(c_{i}^{u_{0}}, c_{i}^{w}, c_{i}^{\theta}, c_{i}^{\psi}\right)$

where $n_{*}, *=u_{0}, w, \theta, \psi$ are the number of shape functions; $c_{i}^{*}$ are the generalized unknowns displacements used to approximate each kinematic variable and $N_{i}(\xi)$ are the shape functions.

These shape functions, $N_{i}(\xi)$, are polynomials expressions and they can be classified in two groups [57], namely: nodal modes for $i=1,2$ and internal modes for $i=3, \ldots, n_{*}$

The nodal modes are the classical support local Lagrange polynomials, i.e.:

$N_{i}(\xi)=\frac{1}{2}\left(1+\xi \xi_{i}\right), \quad i=1,2$

where $\xi_{i}$ is the local coordinate of the $i$-th node.

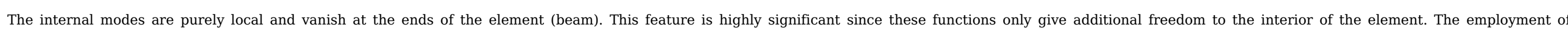

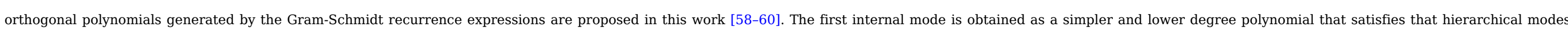
contribute only to the internal components of the displacement field of the element, and do not therefore affect to these components at the end nodes. So the first hierarchical (internal) mode results:

$N_{3}(\xi)=-1+\xi^{2}$

This basis polynomial satisfies $\left.\quad N_{3}(\xi)\right|_{\xi=-1}=\left.N_{3}(\xi)\right|_{\xi=1}=0$ as required.

The remaining hierarchical modes are obtained by the Gram-Schmidt procedure, starting from the basis polynomial (Eq. (15)), as follows $N_{4}(\xi)=\left(\xi-B_{4}\right) N_{3}(\xi)$,

$N_{k}(\xi)=\left(\xi-B_{k}\right) N_{k-1}(\xi)-C_{k} N_{k-2}(\xi)$ for $k=5, \ldots, n_{(*)}$ 


$$
\begin{gathered}
B_{k}=\frac{\int_{-1}^{1} \xi\left(N_{k-1}(\xi)\right)^{2} d \xi}{\int_{-1}^{1}\left(N_{k-1}(\xi)\right)^{2} d \xi}, \text { for } k=4, \ldots, n_{*} \\
C_{k}=\frac{\int_{-1}^{1} \xi N_{k-1}(\xi) N_{k-2}(\xi) d \xi}{\int_{-1}^{1}\left(N_{k-2}(\xi)\right)^{2} d \xi}, \text { for } k=5, \ldots, n_{*}
\end{gathered}
$$

The coefficients of the polynomials are recomputed so that result orthonormal polynomials: $\int_{-1}^{1}\left(N_{k}(\xi)\right)^{2} d \xi=1$

The application of this procedure ensures that higher-order polynomials (hierarchical modes) satisfy, automatically, the same conditions as the basis polynomial.

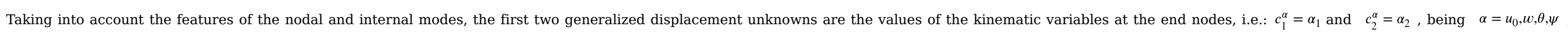

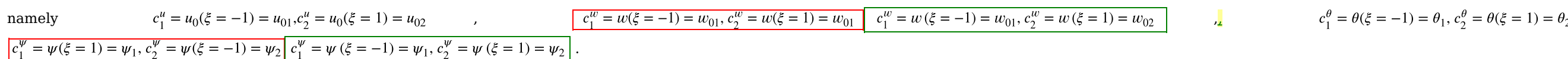

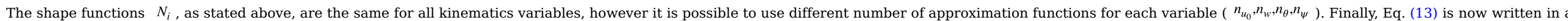
matrix form, as follows

$\mathbf{u}=\left\{\begin{array}{l}u_{0} \\ w \\ \theta \\ \psi\end{array}\right\}=\left\{\begin{array}{l}\mathbf{N}_{u_{0}} \mathbf{c}_{0} \\ \mathbf{N}_{w} \mathbf{c}^{w} \\ \mathbf{N}_{\theta} \mathbf{c}^{\theta} \\ \mathbf{N}_{\psi} \mathbf{c}^{\psi}\end{array}\right\}$

where

$\mathbf{N}_{\alpha}=\left[N_{1}, N_{2}, \ldots, N_{n_{*}}\right] \mathbf{N}_{\alpha}=\left[N_{1}, N_{2}, \ldots, N_{n_{\alpha}}\right]$

$\mathbf{c}^{\alpha}=\left\{\begin{array}{cccc}c_{1}^{\alpha} & c_{2}^{\alpha} & \ldots & c_{n_{\alpha}}^{\alpha}\end{array}\right\}^{T}, \quad \alpha=u_{0}, w, \theta, \psi$

Note that the dimensions of $\mathbf{N}_{\alpha}$ depends on the number of shape functions for each kinematic variable $\left(n_{u_{0}}, n_{w}, n_{\theta}, n_{\psi}\right)$

\subsection{Expression of strains and stress}

The strains for the laminated beam (Fig. 1), considering the RZT theory (Fig. 2) given by Eqs. (6) and (7) are:

$\varepsilon_{x x}^{(k)}=\frac{d u_{0}}{d x}-z \frac{d \theta}{d x}+\phi^{(k)} \frac{d \psi}{d x}$

$\gamma_{x z}^{(k)}=\left(\frac{d w}{d x}-\theta+\beta^{(k)} \psi\right) \gamma_{x z}^{(k)}=\frac{d w}{d x}-\theta+\beta^{(k)} \psi$ Timoshenko beam theory and $\beta^{(k)}$ is constant across each layer

Eqs. (24) and (25) can be written as

$\varepsilon_{x x}^{(k)}=\mathbf{S}_{p}^{(k)} \varepsilon_{p} ; \quad \gamma_{x z}^{(k)}=\mathbf{S}_{t}^{(k)} \varepsilon_{t}$ 


$$
\begin{aligned}
& \mathbf{S}_{p}^{(k)}=\left[1,-z, \phi^{(k)}\right] ; \quad \varepsilon_{p}=\left[\frac{d u_{0}}{d x}, \frac{d \theta}{d x}, \frac{d \psi}{d x}\right]^{T} \\
& \mathbf{S}_{t}^{(k)}=\left[1,-1, \beta^{(k)}\right] ; \quad \varepsilon_{t}=\left[\frac{d w}{d x}, \theta, \psi\right]^{T}
\end{aligned}
$$

In Eqs. (27) and (28) $\varepsilon_{p}$ and $\varepsilon_{t}$ are, respectively, the generalized in-plane and transverse shear strain vectors, respectively.

Substituting Eq. (13) into the generalized strain vectors (Eqs. (27) and (28)) leads to

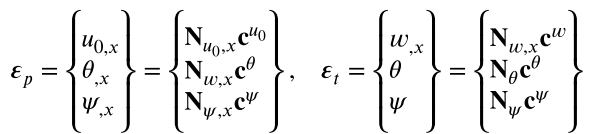

where $\alpha,{ }_{x}$ denotes differentiation with respect to variable $x$

The generalized strain vectors of Eq. (29) can be expressed in other way, which will be convenient for obtaining the global finite hierarchical element equation,

$$
\varepsilon_{p}=\mathbf{B}_{p} \mathbf{c}, \quad \varepsilon_{t}=\mathbf{B}_{t} \mathbf{c}
$$

where $\mathbf{c}$ contains all generalized nodal and internal displacement unknowns (see Eq. (23)); and $\mathbf{B}_{p}, \mathbf{B}_{t}$ are, respectively, the generalized in-plane and transverse shear strain matrices, given by

$\mathbf{c}=\left\{\begin{array}{l}\mathbf{c}^{u_{0}} \\ \mathbf{c}^{w} \\ \mathbf{c}^{\theta} \\ \mathbf{c}^{\psi}\end{array}\right\} ; \quad \mathbf{B}_{p}=\left[\begin{array}{llll}\mathbf{N}_{u_{0}}, x & \mathbf{0} & \mathbf{0} & \mathbf{0} \\ \mathbf{0} & \mathbf{0} & \mathbf{N}_{\theta, x} & \mathbf{0} \\ \mathbf{0} & \mathbf{0} & \mathbf{0} & \mathbf{N}_{\psi}, x\end{array}\right] ; \quad \mathbf{B}_{t}=\left[\begin{array}{cccc}\mathbf{0} & \mathbf{N}_{w}, x & \mathbf{0} & \mathbf{0} \\ \mathbf{0} & \mathbf{0} & \mathbf{N}_{\theta} & \mathbf{0} \\ \mathbf{0} & \mathbf{0} & \mathbf{0} & \mathbf{N}_{\psi}\end{array}\right]$

Replacing Eq. (29) into Eqs. (1) the following stress expressions for the $k$ th layer are obtained

$\sigma_{x x}^{(k)}=\bar{C}_{11}^{(k)} \mathbf{S}_{p}^{(k)} \varepsilon_{p}=\bar{C}_{11}^{(k)} \mathbf{S}_{p}^{(k)} \mathbf{B}_{p} \mathbf{c}$

$\tau_{x z}^{(k)}=\bar{C}_{55}^{(k)} \mathbf{S}_{t}^{(k)} \varepsilon_{t}=\bar{C}_{55}^{(k)} \mathbf{S}_{t}^{(k)} \mathbf{B}_{t} \mathbf{c}$

\subsection{Expression of virtual work}

The virtual work expression for a distributed transverse load $q(x)$, is obtained replacing Eq. (26) into Eq. (5) and integrating the cross sectional area $A$, as follows $\int_{L}\left[\delta \varepsilon_{p}^{T} \mathbf{D}^{p} \varepsilon_{p}+\delta \varepsilon_{t}^{T} \mathbf{D}^{t} \varepsilon_{t}\right] d x-\int_{L} \delta w q d x=0$

where the generalized constitutive matrices $\mathbf{D}^{p}$ and $\mathbf{D}^{t}$ are given by

$$
\begin{aligned}
\mathbf{D}^{p} & =\iint_{A} \bar{C}_{11}^{(k)} \mathbf{S}_{p}^{(k) T} \mathbf{S}_{p}^{(k)} d A=\iint_{A} \bar{C}_{11}^{(k)}\left[\begin{array}{ccc}
1 & -z & \phi^{(k)} \\
& z^{2} & -z \phi^{(k)} \\
s y m & \left(\phi^{(k)}\right)^{2}
\end{array}\right] d A \\
\mathbf{D}^{t} & =\iint_{A} \bar{C}_{55}^{(k)} \mathbf{S}_{t}^{(k) T} \mathbf{S}_{t}^{(k)} d A=\iint_{A} \bar{C}_{55}^{(k)}\left[\begin{array}{ccc}
1 & -1 & \beta^{(k)} \\
& 1 & -\beta^{(k)} \\
\operatorname{sym} & & \left(\beta^{(k)}\right)^{2}
\end{array}\right] d A
\end{aligned}
$$

From Eqs. (21) and (29), the virtual displacement and generalized strain fields are expressed in terms of the virtual nodal modes and internal modes of the kinematic variables,

$$
\delta \mathbf{u}=\left\{\begin{array}{l}
\mathbf{N}_{u_{0}} \delta \mathbf{c}^{u_{0}} \\
\mathbf{N}_{w} \delta \mathbf{c}^{w} \\
\mathbf{N}_{\theta} \delta \mathbf{c}^{\theta} \\
\mathbf{N}_{\psi} \delta \mathbf{c}^{\psi}
\end{array}\right\}, \quad \delta \varepsilon_{p}=\mathbf{B}_{p} \delta \mathbf{c}, \quad \delta \varepsilon_{t}=\mathbf{B}_{t} \delta \mathbf{c}
$$

The discretized equilibrium equations are obtained by substituting Eqs. (30) and (37) into the virtual work expression (Eq. (34)). After simplification of the virtual generalized kinetic unknowns, we obtain 
$\int_{-1}^{1}\left(\mathbf{B}_{p}^{T} \mathbf{D}^{p} \mathbf{B}_{p}+\mathbf{B}_{t}^{T} \mathbf{t}^{t} \mathbf{B}_{t}\right) \mathbf{c} d \xi-\int_{-1}^{1} \mathbf{B}_{f} q d \xi=\mathbf{0}$

where $\mathbf{B}_{f}=\left[\mathbf{0}_{1 \times n_{u}}, \mathbf{N}_{w}, \mathbf{0}_{1 \times n_{\theta}}, \mathbf{0}_{1 \times n_{w}}\right]^{T}$

Expression (38) can be finally expressed in the following classical matrix equation as:

$\mathbf{K c}-\mathbf{f}=\mathbf{0}$

The stiffness matrix $\mathbf{K}$ is the global matrix for the hierarchical finite element, and it is given by

$\mathbf{K}=\int_{-1}^{1} \mathbf{B}^{T} \mathbf{D B} d \xi$

where

$\mathbf{B}^{T}=\left[\mathbf{B}_{p}^{T}, \mathbf{B}_{t}^{T}\right], \quad \mathbf{D}=\left[\begin{array}{cc}\mathbf{D}^{p} & \mathbf{0}_{3 \times 3} \\ \mathbf{0}_{3 \times 3} & \mathbf{D}^{t}\end{array}\right]$

The equivalent force vector $\mathbf{f}$ results:

$\mathbf{f}=\left[\mathbf{0}_{1 \times n_{u}}, \mathbf{f}^{w}, \mathbf{0}_{1 \times n_{\theta}}, \mathbf{0}_{1 \times n_{\psi}}\right]^{T}$

where $f_{i}^{v}=\int_{-1}^{1} q N_{i} d \xi, i=1, n_{w}$

The stiffness matrix $\mathbf{K}$ in Eq. (40), can be easily expressed as follows:

$\mathbf{K}=\left[\begin{array}{cccc}\mathbf{k}^{u u} & \mathbf{0} & \mathbf{k}^{u \theta} & \mathbf{k}^{u \psi} \\ & \mathbf{k}^{w w} & \mathbf{k}^{w \theta} & \mathbf{k}^{w \psi} \\ & & \mathbf{k}^{\theta \theta} & \mathbf{k}^{\psi \omega} \\ \text { sym } & & & \mathbf{k}^{\psi \psi}\end{array}\right]$

where their respective components are:

$k_{i j}^{u u}=D_{11}^{p} \frac{4}{L^{2}} \int_{-1}^{1} \frac{d N_{i}}{d \xi} \frac{d N_{j}}{d \xi} d \xi, \quad i=1, n_{u} ; \quad j=1, n_{u}$

$k_{i j}^{u \theta}=D_{12}^{p} \frac{4}{L^{2}} \int_{-1}^{1} \frac{d N_{i}}{d \xi} \frac{d N_{j}}{d \xi} d \xi, \quad i=1, n_{u} ; \quad j=1, n_{\theta}$

$k_{i j}^{u \psi}=D_{13}^{p} \frac{4}{L^{2}} \int_{-1}^{1} \frac{d N_{i}}{d \xi} \frac{d N_{j}}{d \xi} d \xi, \quad i=1, n_{u} ; \quad j=1, n_{\psi}$

$k_{i j}^{w w}=D_{11}^{t} \frac{4}{L^{2}} \int_{-1}^{1} \frac{d N_{i}}{d \xi} \frac{d N_{j}}{d \xi} d \xi, \quad i=1, n_{w} ; \quad j=1, n_{w}$

$k_{i j}^{w \theta}=D_{12}^{t} \frac{2}{L} \int_{-1}^{1} \frac{d N_{i}}{d \xi} N_{j} d \xi, \quad i=1, n_{w} ; \quad j=1, n_{\theta}$

$k_{i j}^{w \psi}=D_{13}^{t} \frac{2}{L} \int_{-1}^{1} \frac{d N_{i}}{d \xi} N_{j} d \xi, \quad i=1, n_{w} ; \quad j=1, n_{\psi}$

$k_{i j}^{\theta \theta}=D_{22}^{p} \frac{4}{L^{2}} \int_{-1}^{1} \frac{d N_{i}}{d \xi} \frac{d N_{j}}{d \xi} d \xi+D_{22}^{t} \int_{-1}^{1} N_{i} N_{j} d \xi, \quad i=1, n_{\theta} ; \quad j=1, n_{\theta}$

$k_{i j}^{\theta \psi}=D_{23}^{p} \frac{4}{L^{2}} \int_{-1}^{1} \frac{d N_{i}}{d \xi} \frac{d N_{j}}{d \xi} d \xi+D_{23}^{t} \int_{-1}^{1} N_{i} N_{j} d \xi, \quad i=1, n_{\theta} ; \quad j=1, n_{\psi}$

$k_{i j}^{\psi \psi}=D_{33}^{p} \frac{4}{L^{2}} \int_{-1}^{1} \frac{d N_{i}}{d \xi} \frac{d N_{j}}{d \xi} d \xi+D_{33}^{t} \int_{-1}^{1} N_{i} N_{j} d \xi, \quad i=1, n_{\psi} ; \quad j=1, n_{\psi}$

(42)

The new hierarchical beam finite element based on RZT Tessler developments is termed PRZ. Studies of shear locking, convergence and validations are presented in the next sections.

\section{Study shear locking for PRZ element}

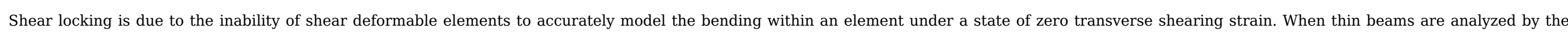




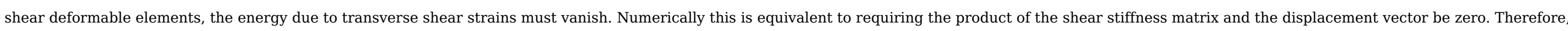

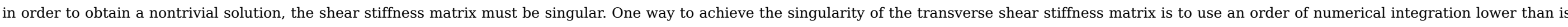

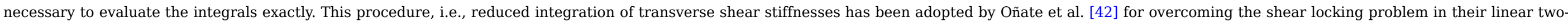

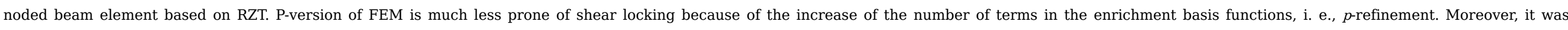
theoretically and numerically shown, that the $p$-version is free of locking effects, if the polynomial degree is chosen to be moderately high.

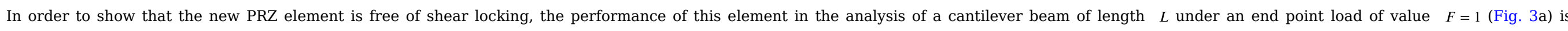

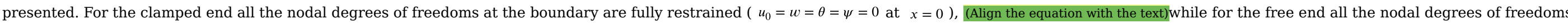
are unrestrained. The material properties correspond to that designated as Composite B in Table 1.

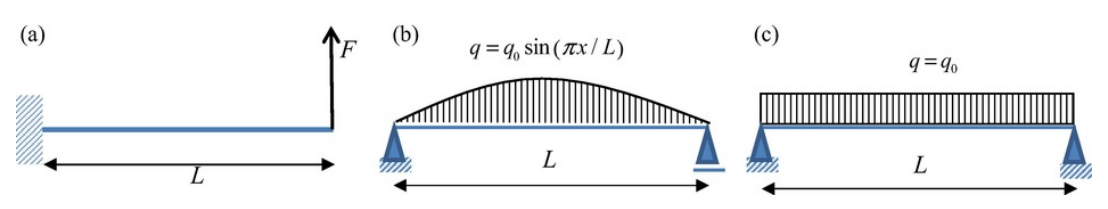

Fig. 3 Structural representation of the analyzed beams; (a) Cantilever beam under a free end point load, (b) Simple supported beam under sinusoidal load, (c) Simple supported beam under uniform load.

Table 1 Material properties of 3-layered symmetric and non-symmetric laminates.

\begin{tabular}{|c|c|c|c|c|}
\hline \multicolumn{2}{|c|}{ Composite } & \multicolumn{3}{|c|}{ Material Properties } \\
\hline & & Layer 1 (bottom) & Layer 2 (core) & Layer 3 (top) \\
\hline \multirow[t]{3}{*}{ (A) Non-Symmetric laminate } & $h^{(k)}[\mathrm{mm}]$ & 6.66 & 6.66 & 6.66 \\
\hline & $E^{(k)}[\mathrm{MPa}]$ & $4.40 \mathrm{E}+05$ & $2.19 \mathrm{E}+04$ & $2.19 \mathrm{E}+05$ \\
\hline & $G_{x z}^{(k)}[\mathrm{MPa}]$ & $2.00 \mathrm{E}+05$ & $8.80 \mathrm{E}+03$ & $8.76 \mathrm{E}+04$ \\
\hline \multirow[t]{3}{*}{ (B) Symmetric laminate } & $h^{(k)}[\mathrm{mm}]$ & 6.66 & 6.66 & 6.66 \\
\hline & $E^{(k)}[\mathrm{MPa}]$ & $2.19 \mathrm{E} 5$ & $2.19 \mathrm{E} 3$ & $2.19 \mathrm{E} 5$ \\
\hline & $G_{x z}^{(k)}[\mathrm{MPa}]$ & $8.76 \mathrm{E} 4$ & $8.80 \mathrm{E} 2$ & $8.76 \mathrm{E} 4$ \\
\hline \multirow[t]{3}{*}{ (C) Non-symmetric laminate } & $h^{(k)}[\mathrm{mm}]$ & 2 & 16 & 2 \\
\hline & $E^{(k)}[\mathrm{MPa}]$ & 7.30E5 & 7.30E2 & $2.19 \mathrm{E} 5$ \\
\hline & $G_{x z}^{(k)}[\mathrm{MPa}]$ & 2.92E5 & $2.90 \mathrm{E} 2$ & $8.76 \mathrm{E} 4$ \\
\hline \multirow[t]{3}{*}{ (D) Non-symmetric laminate } & $h^{(k)}[\mathrm{mm}]$ & 6.6666 & 6.6666 & 6.6666 \\
\hline & $E^{(k)}[\mathrm{MPa}]$ & $2.19 \mathrm{E} 5$ & $5.30 \mathrm{E} 5$ & 7.30E5 \\
\hline & $G_{x z}^{(k)}[\mathrm{MPa}]$ & $8.76 \mathrm{E} 4$ & $2.90 \mathrm{E} 2$ & $2.92 \mathrm{E} 2$ \\
\hline
\end{tabular}




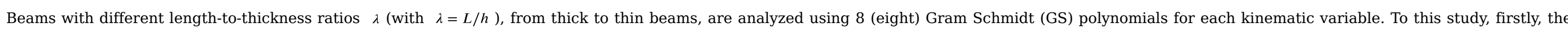
free end deflection is analyzed and the following dimensionless variable is used:

$\left.\bar{w}\right|_{x=L}=\frac{w \bar{E}}{10 F \lambda^{3}}$

where $\bar{E}=\frac{1}{N_{l}} \sum_{k=1}^{N_{l}} E_{x}^{(k)} \bar{E}=\frac{1}{N_{l}} \sum_{k=1}^{N_{l}} E^{(k)}$

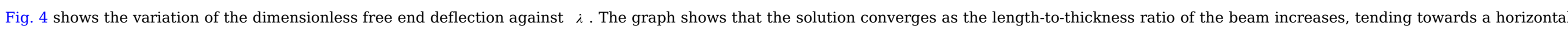

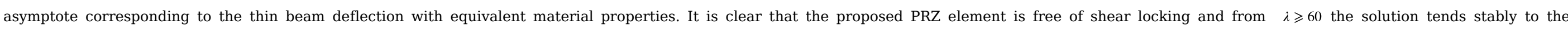
corresponding solution for thin beams.

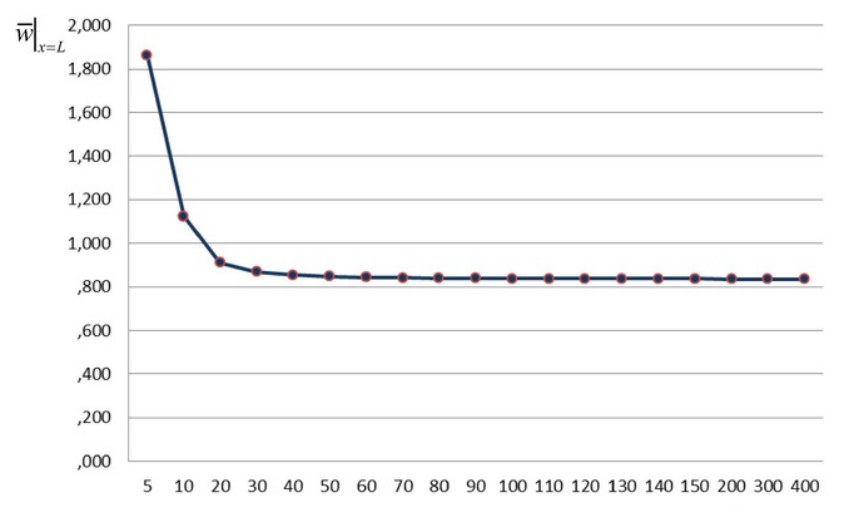

$\lambda$

Fig. 4 Free end deflection $\bar{w}$ for a laminated cantilever beam (Composite B) for different length - to - thickness ratios

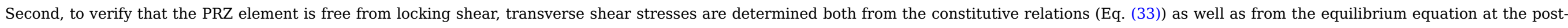
processing level i.e.,

$\tau_{x z}^{(k)}(z)=-\int_{-h / 2}^{z} \frac{\partial \sigma_{x x}^{(k)}}{\partial x} d z$

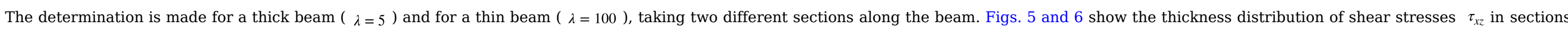

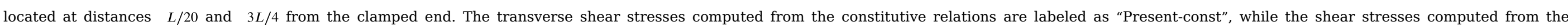

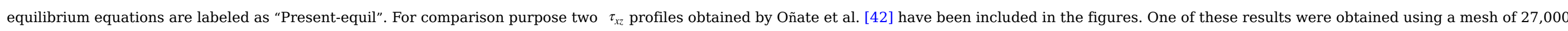

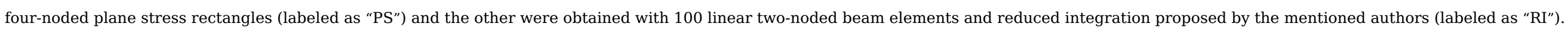



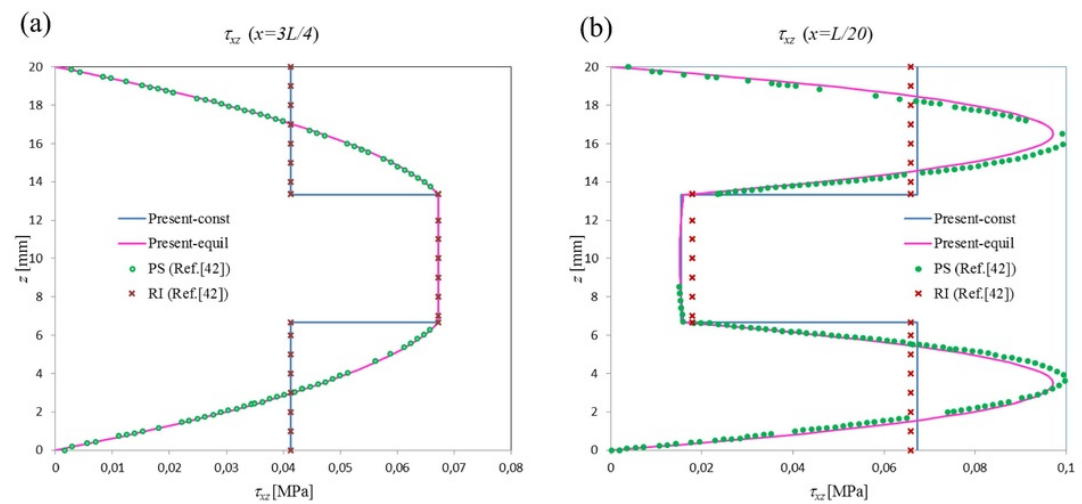

Fig. 5 Symmetric (composite B) cantilever thick beam ( $\lambda=5$ ) under end point load. Thickness distribution of shear stress at different sections.
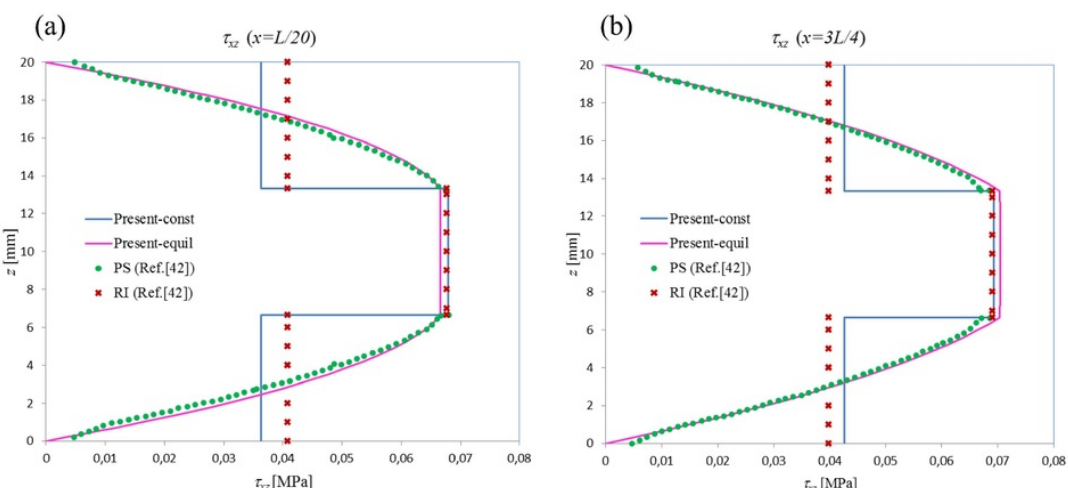

Fig. 6 Symmetric (composite B) cantilever thin beam ( $\lambda=100)$ under end point load. Thickness distribution of shear stress at different sections.

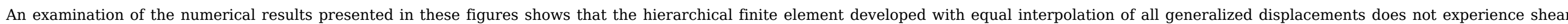

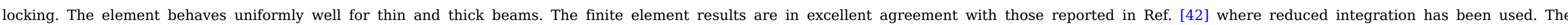
displacements converge faster than stresses, which is expected because the rate of convergence of gradients of the solution is one order less than the rate of convergence of the solution.

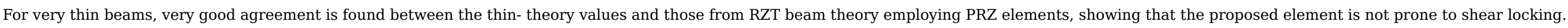

\section{Convergence analysis}

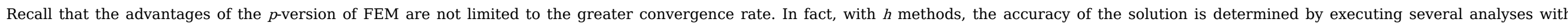

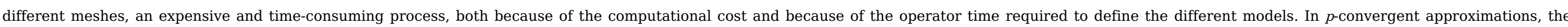

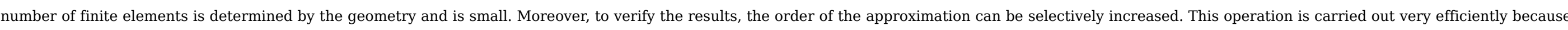
it is not necessary to generate a new mesh and because the new linear stiffness matrices contain the preceding ones [55].

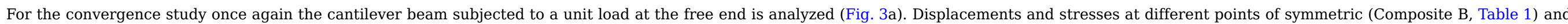

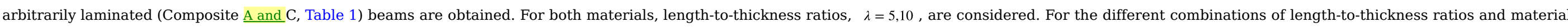
properties, convergence studies are performed by varying the amount of GS orthogonal polynomials of the approximation functions for the four kinematic variables, from 1 to 10. 


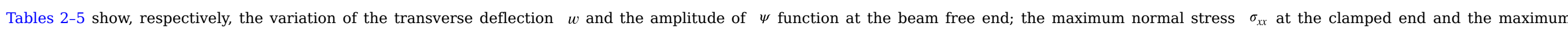

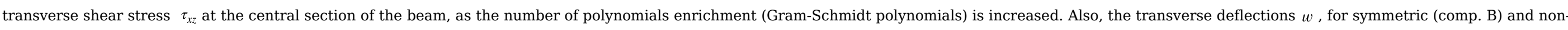
symmetric (comp. C) laminated beams with length - to - thickness ratio $\lambda=5$, are plotted against the number of GS enrichment polynomials in Fig. 7 .

Table 2 Convergence study of three layered symmetric and non-symmetric cantilever thick beams. Relative error for $w$ at $x=L$ for increasing number of GS polynomials.

\begin{tabular}{|c|c|c|c|c|c|c|}
\hline \multicolumn{7}{|c|}{ Composites } \\
\hline \multirow[b]{2}{*}{$\lambda=L / h$} & \multicolumn{2}{|c|}{$\mathrm{A}$} & \multicolumn{2}{|c|}{ B } & \multicolumn{2}{|c|}{$\mathrm{C}$} \\
\hline & 5 & 10 & 5 & 10 & 5 & 10 \\
\hline \multicolumn{7}{|l|}{$e_{r}(\%)-w(x=L)$} \\
\hline 1 & 13.961 & 19.044 & 14.390 & 15.734 & 17.446 & 17.104 \\
\hline 2 & 0.576 & 0.226 & 1.161 & 1.019 & 4.151 & 3.918 \\
\hline 3 & 0.168 & 0.102 & 0.138 & 0.271 & 1.088 & 1.533 \\
\hline 4 & 0.040 & 0.043 & 0.010 & 0.058 & 0.232 & 0.585 \\
\hline 5 & 0.008 & 0.017 & 0.001 & 0.009 & 0.038 & 0.203 \\
\hline 6 & 0.001 & 0.006 & 0.000 & 0.001 & 0.005 & 0.062 \\
\hline 7 & 0.000 & 0.002 & 0.000 & 0.000 & 0.001 & 0.016 \\
\hline 8 & 0.000 & 0.000 & 0.000 & 0.000 & 0.000 & 0.004 \\
\hline 9 & 0.000 & 0.000 & 0.000 & 0.000 & 0.000 & 0.001 \\
\hline 10 & 0.000 & 0.000 & 0.000 & 0.000 & 0.000 & 0.000 \\
\hline
\end{tabular}

Table 3 Convergence study of three layered symmetric and non-symmetric cantilever thick beams. Relative error for $\psi$ at $x=L$ for increasing number of GS polynomials.

\begin{tabular}{|c|c|c|c|c|c|c|}
\hline \multicolumn{7}{|c|}{ Composites } \\
\hline \multirow[b]{2}{*}{$\lambda=L / h$} & \multicolumn{2}{|c|}{$\mathrm{A}$} & \multicolumn{2}{|c|}{ B } & \multicolumn{2}{|c|}{$\mathrm{C}$} \\
\hline & 5 & 10 & 5 & 10 & 5 & 10 \\
\hline \multicolumn{7}{|l|}{$e_{r}(\%)-\psi(x=L)$} \\
\hline 1 & 100.372 & 194.748 & 45.084 & 95.026 & 17.446 & 49.393 \\
\hline 2 & 8.942 & 2.563 & 6.516 & 14.863 & 4.151 & 20.340 \\
\hline 3 & 4.214 & 5.082 & 0.870 & 5.662 & 1.088 & 7.196 \\
\hline 4 & 1.306 & 3.913 & 0.070 & 1.445 & 0.232 & 1.793 \\
\hline 5 & 0.290 & 2.178 & 0.004 & 0.263 & 0.038 & 0.324 \\
\hline 6 & 0.049 & 0.945 & 0.000 & 0.036 & 0.005 & 0.044 \\
\hline 7 & 0.006 & 0.348 & 0.000 & 0.004 & 0.001 & 0.005 \\
\hline
\end{tabular}




\begin{tabular}{|c|c|c|c|c|c|c|}
\hline 8 & 0.001 & 0.098 & 0.000 & 0.000 & 0.000 & 0.000 \\
\hline 9 & 0.000 & 0.033 & 0.000 & 0.000 & 0.000 & 0.000 \\
\hline 10 & 0.000 & 0.000 & 0.000 & 0.000 & 0.000 & 0.000 \\
\hline
\end{tabular}

Table 4 Convergence study of three layered symmetric and non-symmetric cantilever thick beams. Relative error for $\left(\sigma_{x x}\right)_{\max }$ at $x=0$ for increasing number of GS polynomials.

Composites

A

10

\begin{tabular}{|c|c|c|c|c|c|c|}
\hline \multicolumn{7}{|l|}{$e_{r}(\%)-\left(\sigma_{x x}\right)_{\max }(x=0)$} \\
\hline 1 & 99.924 & 45.979 & 43.141 & 42.285 & 69.413 & 64.480 \\
\hline 2 & 17.108 & 12.346 & 18.176 & 18.403 & 50.243 & 51.041 \\
\hline 3 & 11.051 & 9.952 & 7.225 & 11.445 & 32.314 & 40.928 \\
\hline 4 & 6.091 & 7.484 & 0.499 & 5.972 & 17.253 & 30.229 \\
\hline 5 & 2.843 & 5.167 & 0.499 & 2.600 & 7.638 & 20.146 \\
\hline 6 & 1.139 & 3.224 & 0.097 & 0.963 & 2.869 & 11.941 \\
\hline 7 & 0.397 & 1.785 & 0.016 & 0.309 & 0.933 & 6.217 \\
\hline 8 & 0.119 & 0.843 & 0.002 & 0.085 & 0.261 & 1.752 \\
\hline 9 & 0.027 & 0.292 & 0.000 & 0.018 & 0.056 & 0.896 \\
\hline 10 & 0.000 & 0.000 & 0.000 & 0.000 & 0.000 & 0.000 \\
\hline \multicolumn{7}{|c|}{ Composites } \\
\hline & \multicolumn{2}{|c|}{$\mathrm{A}$} & \multicolumn{2}{|c|}{$\mathrm{B}$} & \multicolumn{2}{|c|}{$\mathrm{C}$} \\
\hline$\lambda=L / h$ & 5 & 10 & 5 & 10 & 5 & \\
\hline \multicolumn{7}{|c|}{$e_{r}(\%)-\left(\tau_{x z}\right)_{\max }(x=L / 2)$} \\
\hline 1 & 99.991 & 95.894 & 33.693 & 53.549 & 176.151 & 35.364 \\
\hline 2 & 8.925 & 10.899 & 2.814 & 8.625 & 44.083 & 13.875 \\
\hline 3 & 4.115 & 3.166 & 2.422 & 5.496 & 9.007 & 8.638 \\
\hline 4 & 1.797 & 4.317 & 0.180 & 1.336 & 1.336 & 4.114 \\
\hline 5 & 0.942 & 2.105 & 0.116 & 1.022 & 1.243 & 3.550 \\
\hline 6 & 0.248 & 1.353 & 0.005 & 0.136 & 0.134 & 1.063 \\
\hline
\end{tabular}

B

5

\begin{tabular}{|c|c|c|c|c|c|c|}
\hline \multicolumn{7}{|l|}{$e_{r}(\%)-\left(\sigma_{x x}\right)_{\max }(x=0)$} \\
\hline 1 & 99.924 & 45.979 & 43.141 & 42.285 & 69.413 & 64.480 \\
\hline 2 & 17.108 & 12.346 & 18.176 & 18.403 & 50.243 & 51.041 \\
\hline 3 & 11.051 & 9.952 & 7.225 & 11.445 & 32.314 & 40.928 \\
\hline 4 & 6.091 & 7.484 & 0.499 & 5.972 & 17.253 & 30.229 \\
\hline 5 & 2.843 & 5.167 & 0.499 & 2.600 & 7.638 & 20.146 \\
\hline 6 & 1.139 & 3.224 & 0.097 & 0.963 & 2.869 & 11.941 \\
\hline 7 & 0.397 & 1.785 & 0.016 & 0.309 & 0.933 & 6.217 \\
\hline 8 & 0.119 & 0.843 & 0.002 & 0.085 & 0.261 & 1.752 \\
\hline 9 & 0.027 & 0.292 & 0.000 & 0.018 & 0.056 & 0.896 \\
\hline 10 & 0.000 & 0.000 & 0.000 & 0.000 & 0.000 & 0.000 \\
\hline \multicolumn{7}{|c|}{ Composites } \\
\hline & \multicolumn{2}{|c|}{$\mathrm{A}$} & \multicolumn{2}{|c|}{$\mathrm{B}$} & \multicolumn{2}{|c|}{$\mathrm{C}$} \\
\hline$\lambda=L / h$ & 5 & 10 & 5 & 10 & 5 & \\
\hline \multicolumn{7}{|c|}{$e_{r}(\%)-\left(\tau_{x z}\right)_{\max }(x=L / 2)$} \\
\hline 1 & 99.991 & 95.894 & 33.693 & 53.549 & 176.151 & 35.364 \\
\hline 2 & 8.925 & 10.899 & 2.814 & 8.625 & 44.083 & 13.875 \\
\hline 3 & 4.115 & 3.166 & 2.422 & 5.496 & 9.007 & 8.638 \\
\hline 4 & 1.797 & 4.317 & 0.180 & 1.336 & 1.336 & 4.114 \\
\hline 5 & 0.942 & 2.105 & 0.116 & 1.022 & 1.243 & 3.550 \\
\hline 6 & 0.248 & 1.353 & 0.005 & 0.136 & 0.134 & 1.063 \\
\hline
\end{tabular}

10

\begin{tabular}{|c|c|c|c|c|c|c|}
\hline \multicolumn{7}{|l|}{$e_{r}(\%)-\left(\sigma_{x x}\right)_{\max }(x=0)$} \\
\hline 1 & 99.924 & 45.979 & 43.141 & 42.285 & 69.413 & 64.480 \\
\hline 2 & 17.108 & 12.346 & 18.176 & 18.403 & 50.243 & 51.041 \\
\hline 3 & 11.051 & 9.952 & 7.225 & 11.445 & 32.314 & 40.928 \\
\hline 4 & 6.091 & 7.484 & 0.499 & 5.972 & 17.253 & 30.229 \\
\hline 5 & 2.843 & 5.167 & 0.499 & 2.600 & 7.638 & 20.146 \\
\hline 6 & 1.139 & 3.224 & 0.097 & 0.963 & 2.869 & 11.941 \\
\hline 7 & 0.397 & 1.785 & 0.016 & 0.309 & 0.933 & 6.217 \\
\hline 8 & 0.119 & 0.843 & 0.002 & 0.085 & 0.261 & 1.752 \\
\hline 9 & 0.027 & 0.292 & 0.000 & 0.018 & 0.056 & 0.896 \\
\hline 10 & 0.000 & 0.000 & 0.000 & 0.000 & 0.000 & 0.000 \\
\hline \multicolumn{7}{|c|}{ Composites } \\
\hline & \multicolumn{2}{|c|}{$\mathrm{A}$} & \multicolumn{2}{|c|}{$\mathrm{B}$} & \multicolumn{2}{|c|}{$\mathrm{C}$} \\
\hline$\lambda=L / h$ & 5 & 10 & 5 & 10 & 5 & \\
\hline \multicolumn{7}{|c|}{$e_{r}(\%)-\left(\tau_{x z}\right)_{\max }(x=L / 2)$} \\
\hline 1 & 99.991 & 95.894 & 33.693 & 53.549 & 176.151 & 35.364 \\
\hline 2 & 8.925 & 10.899 & 2.814 & 8.625 & 44.083 & 13.875 \\
\hline 3 & 4.115 & 3.166 & 2.422 & 5.496 & 9.007 & 8.638 \\
\hline 4 & 1.797 & 4.317 & 0.180 & 1.336 & 1.336 & 4.114 \\
\hline 5 & 0.942 & 2.105 & 0.116 & 1.022 & 1.243 & 3.550 \\
\hline 6 & 0.248 & 1.353 & 0.005 & 0.136 & 0.134 & 1.063 \\
\hline
\end{tabular}

C

5

\begin{tabular}{|c|c|c|c|c|c|c|}
\hline \multicolumn{7}{|l|}{$e_{r}(\%)-\left(\sigma_{x x}\right)_{\max }(x=0)$} \\
\hline 1 & 99.924 & 45.979 & 43.141 & 42.285 & 69.413 & 64.480 \\
\hline 2 & 17.108 & 12.346 & 18.176 & 18.403 & 50.243 & 51.041 \\
\hline 3 & 11.051 & 9.952 & 7.225 & 11.445 & 32.314 & 40.928 \\
\hline 4 & 6.091 & 7.484 & 0.499 & 5.972 & 17.253 & 30.229 \\
\hline 5 & 2.843 & 5.167 & 0.499 & 2.600 & 7.638 & 20.146 \\
\hline 6 & 1.139 & 3.224 & 0.097 & 0.963 & 2.869 & 11.941 \\
\hline 7 & 0.397 & 1.785 & 0.016 & 0.309 & 0.933 & 6.217 \\
\hline 8 & 0.119 & 0.843 & 0.002 & 0.085 & 0.261 & 1.752 \\
\hline 9 & 0.027 & 0.292 & 0.000 & 0.018 & 0.056 & 0.896 \\
\hline 10 & 0.000 & 0.000 & 0.000 & 0.000 & 0.000 & 0.000 \\
\hline \multicolumn{7}{|c|}{ Composites } \\
\hline & \multicolumn{2}{|c|}{$\mathrm{A}$} & \multicolumn{2}{|c|}{$\mathrm{B}$} & \multicolumn{2}{|c|}{$\mathrm{C}$} \\
\hline$\lambda=L / h$ & 5 & 10 & 5 & 10 & 5 & \\
\hline \multicolumn{7}{|c|}{$e_{r}(\%)-\left(\tau_{x z}\right)_{\max }(x=L / 2)$} \\
\hline 1 & 99.991 & 95.894 & 33.693 & 53.549 & 176.151 & 35.364 \\
\hline 2 & 8.925 & 10.899 & 2.814 & 8.625 & 44.083 & 13.875 \\
\hline 3 & 4.115 & 3.166 & 2.422 & 5.496 & 9.007 & 8.638 \\
\hline 4 & 1.797 & 4.317 & 0.180 & 1.336 & 1.336 & 4.114 \\
\hline 5 & 0.942 & 2.105 & 0.116 & 1.022 & 1.243 & 3.550 \\
\hline 6 & 0.248 & 1.353 & 0.005 & 0.136 & 0.134 & 1.063 \\
\hline
\end{tabular}

Table 5 Convergence study of three layered symmetric and non-symmetric cantilever thick beams. Relative error for $\left(\tau_{x z}\right)_{\max }$ at $x=L / 2$ for increasing number of GS polynomials.

\begin{tabular}{|c|c|c|c|c|c|c|}
\hline \multicolumn{7}{|l|}{$e_{r}(\%)-\left(\sigma_{x x}\right)_{\max }(x=0)$} \\
\hline 1 & 99.924 & 45.979 & 43.141 & 42.285 & 69.413 & 64.480 \\
\hline 2 & 17.108 & 12.346 & 18.176 & 18.403 & 50.243 & 51.041 \\
\hline 3 & 11.051 & 9.952 & 7.225 & 11.445 & 32.314 & 40.928 \\
\hline 4 & 6.091 & 7.484 & 0.499 & 5.972 & 17.253 & 30.229 \\
\hline 5 & 2.843 & 5.167 & 0.499 & 2.600 & 7.638 & 20.146 \\
\hline 6 & 1.139 & 3.224 & 0.097 & 0.963 & 2.869 & 11.941 \\
\hline 7 & 0.397 & 1.785 & 0.016 & 0.309 & 0.933 & 6.217 \\
\hline 8 & 0.119 & 0.843 & 0.002 & 0.085 & 0.261 & 1.752 \\
\hline 9 & 0.027 & 0.292 & 0.000 & 0.018 & 0.056 & 0.896 \\
\hline 10 & 0.000 & 0.000 & 0.000 & 0.000 & 0.000 & 0.000 \\
\hline \multicolumn{7}{|c|}{ Composites } \\
\hline & \multicolumn{2}{|c|}{$\mathrm{A}$} & \multicolumn{2}{|r|}{ B } & \multicolumn{2}{|c|}{$\mathrm{C}$} \\
\hline$\lambda=L / h$ & 5 & 10 & 5 & 10 & 5 & \\
\hline \multicolumn{7}{|c|}{$e_{r}(\%)-\left(\tau_{x z}\right)_{\max }(x=L / 2)$} \\
\hline 1 & 99.991 & 95.894 & 33.693 & 53.549 & 176.151 & 35.364 \\
\hline 2 & 8.925 & 10.899 & 2.814 & 8.625 & 44.083 & 13.875 \\
\hline 3 & 4.115 & 3.166 & 2.422 & 5.496 & 9.007 & 8.638 \\
\hline 4 & 1.797 & 4.317 & 0.180 & 1.336 & 1.336 & 4.114 \\
\hline 5 & 0.942 & 2.105 & 0.116 & 1.022 & 1.243 & 3.550 \\
\hline 6 & 0.248 & 1.353 & 0.005 & 0.136 & 0.134 & 1.063 \\
\hline
\end{tabular}




\begin{tabular}{|c|c|c|c|c|c|c|}
\hline 7 & 0.119 & 0.707 & 0.003 & 0.103 & 0.127 & 1.013 \\
\hline 8 & 0.024 & 0.458 & 0.000 & 0.010 & 0.009 & 0.264 \\
\hline 9 & 0.011 & 0.288 & 0.000 & 0.007 & 0.009 & 0.256 \\
\hline 10 & 0.000 & 0.000 & 0.000 & 0.000 & 0.000 & 0.000 \\
\hline
\end{tabular}

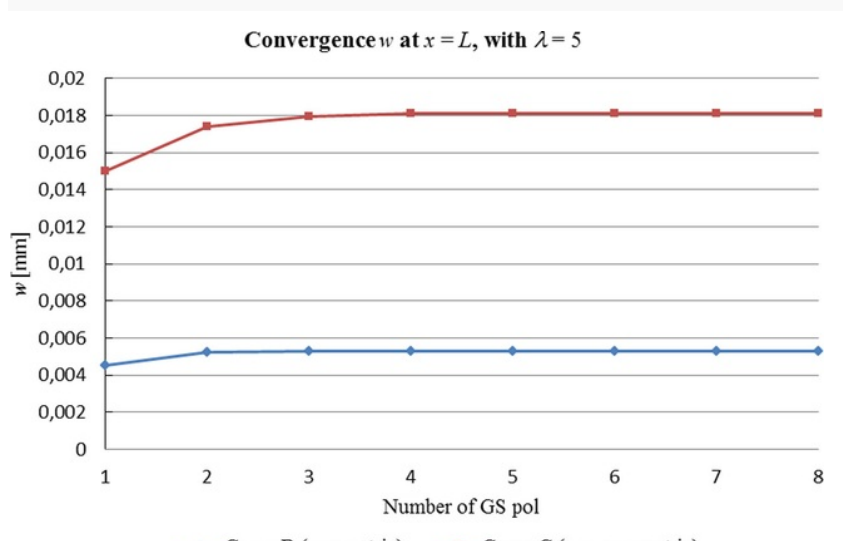

$\rightarrow$ Comp B (symmetric) $\rightarrow$ Comp C (non-symmetric)

Fig. 7 Transverse free end deflection $w$ for different layer sequence: convergence study for $\lambda=5$.

In Tables 2-5 the convergence is quantified through the relative error given by the following expression $e_{r}=\left|\frac{v_{10}-v_{i}}{v_{10}}\right|$

where $v_{10}$ and $\mathrm{y} v_{i}$ are the numerical values of the different magnitudes obtained employing 10 GS polynomials and $i(i=1, \ldots, 10)$ GS polynomials, respectively.

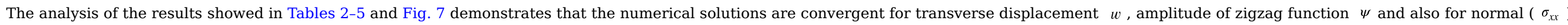

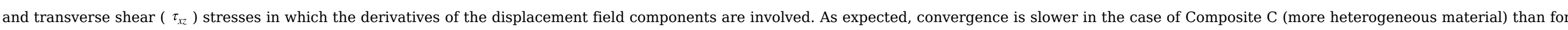

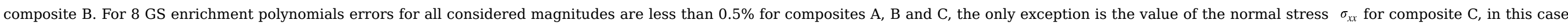
the error is less than $1.8 \%$. For these reasons, the calculations using eight GS enrichment polynomials for each kinematic variable, is considered sufficient to obtain good accuracy.

\section{Validation and numerical examples}

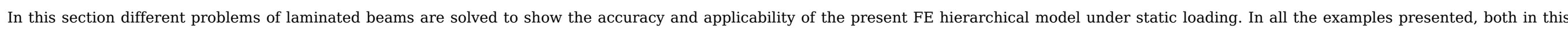

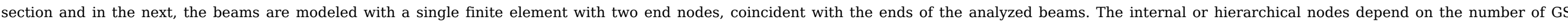
polynomials used in each case and are obtained automatically (see Eqs. (39)-(43)).

\subsection{Symmetric and antisymmetric cross-ply laminated beams}

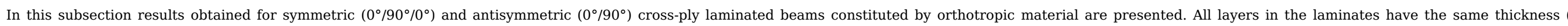

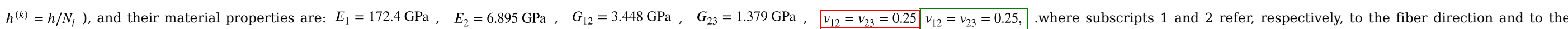
normal direction.

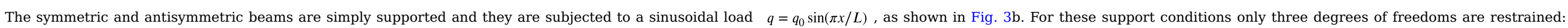

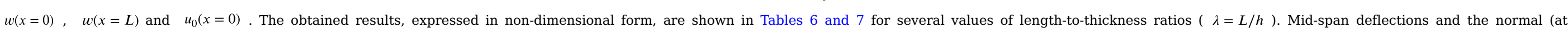




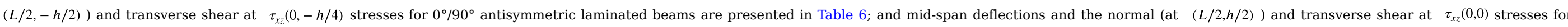

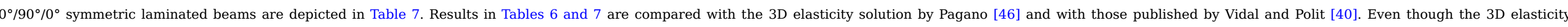

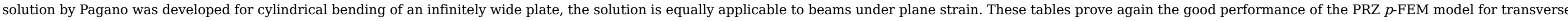

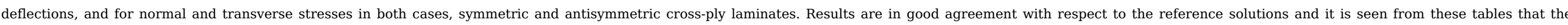
element performs quite well for thick beams as well as thin beams, as has been previously remarked (Section 5).

Table 6 Non-dimensional displacements and stresses of antisymmetric $0^{\circ} / 90^{\circ}$ cross-ply beam under sinusoidal load for different values of $\lambda$.

\begin{tabular}{|c|c|c|c|c|c|c|c|}
\hline$\lambda$ & 4 & 6 & 8 & 10 & 20 & 40 & 100 \\
\hline \multicolumn{8}{|l|}{$100 w(L / 2) E_{2} h^{3} / q_{0} L^{4}$} \\
\hline Present (PRZ) & 4.5137 & 3.4687 & 3.1006 & 2.9298 & 2.7014 & 2.6442 & 2.6282 \\
\hline Ref. [40] & 4.5438 & - & - & - & 2.7036 & 2.6450 & - \\
\hline Ref. [46] & 4.7076 & 3.5600 & 3.1504 & 2.9596 & 2.7092 & 2.6462 & 2.6220 \\
\hline \multicolumn{8}{|l|}{$\sigma_{x x}(L / 2,-h / 2) / q_{0}$} \\
\hline Present (PRZ) & 26.748 & 61.490 & 110.27 & 173.03 & 696.22 & 2789.2 & 17439.7 \\
\hline Ref. [40] & 31.8 & - & - & - & 703.6 & 2803.1 & - \\
\hline Ref. [46] & 30.0 & 65.382 & 114.18 & 176.95 & 699.7 & 2792.6 & 17443.7 \\
\hline \multicolumn{8}{|l|}{$\tau_{x z}(0,-h / 4) / q_{0}$} \\
\hline Present (PRZ) & 2.8396 & 4.3315 & 5.8146 & 7.2926 & 14.653 & 29.341 & 73.378 \\
\hline Ref. [40] & 2.843 & - & - & - & 14.574 & 29.174 & - \\
\hline Ref. [46] & 2.706 & 4.2532 & 5.7528 & 7.2419 & 14.620 & 29.325 & 73.373 \\
\hline
\end{tabular}

Table 7 Non-dimensional displacements and stresses of symmetric $0^{\circ} / 90^{\circ} / 0^{\circ}$ cross-ply beam under sinusoidal load for different values of $\lambda$.

\begin{tabular}{|c|c|c|c|c|c|c|c|}
\hline$\lambda$ & 4 & 6 & 8 & 10 & 20 & 40 & 100 \\
\hline \multicolumn{8}{|l|}{$100 w(L / 2) E_{2} h^{3} / q_{0} L^{4}$} \\
\hline Present (PRZ) & 2.8031 & 1.5898 & 1.1329 & 0.9139 & 0.6134 & 0.5366 & 0.5150 \\
\hline Ref. [40] & 2.8027 & - & - & - & 0.6151 & 0.5371 & - \\
\hline Ref. [46] & 2.8899 & 1.6345 & 1.1598 & 0.9316 & 0.6185 & 0.5379 & 0.5139 \\
\hline \multicolumn{8}{|l|}{$\sigma_{x x}(L / 2, h / 2) / q_{0}$} \\
\hline Present (PRZ) & 16.195 & 29.968 & 48.138 & 71.097 & 260.59 & 1017.1 & 6311.97 \\
\hline Ref. [40] & 19.5 & - & - & - & 265.4 & 1024.4 & - \\
\hline
\end{tabular}




\begin{tabular}{|c|c|c|c|c|c|c|c|}
\hline Ref. [46] & 18.809 & 32.531 & 50.704 & 73.672 & 263.2 & 1019.7 & 6314.58 \\
\hline \multicolumn{8}{|l|}{$\tau_{x z}(0,0) / q_{0}$} \\
\hline Present (PRZ) & 1.4358 & 2.3890 & 3.3255 & 4.2467 & 8.7530 & 17.644 & 44.207 \\
\hline Ref. [40] & 1.4202 & - & - & - & 8.6988 & 17.5400 & - \\
\hline Ref. [46] & 1.4318 & 2.3805 & 3.3167 & 4.2385 & 8.7483 & 17.641 & 44.206 \\
\hline
\end{tabular}

\subsection{Three layered thick cantilever beam under end point load, with non-symmetric material properties}

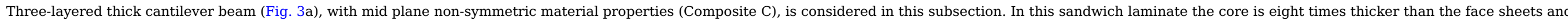

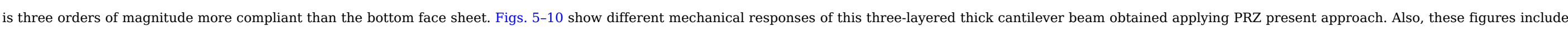
plane stress results reported in [42], where legend caption PS denotes these reference solutions obtained with meshes of 27,000 four-noded plane stress quadrilaterals.

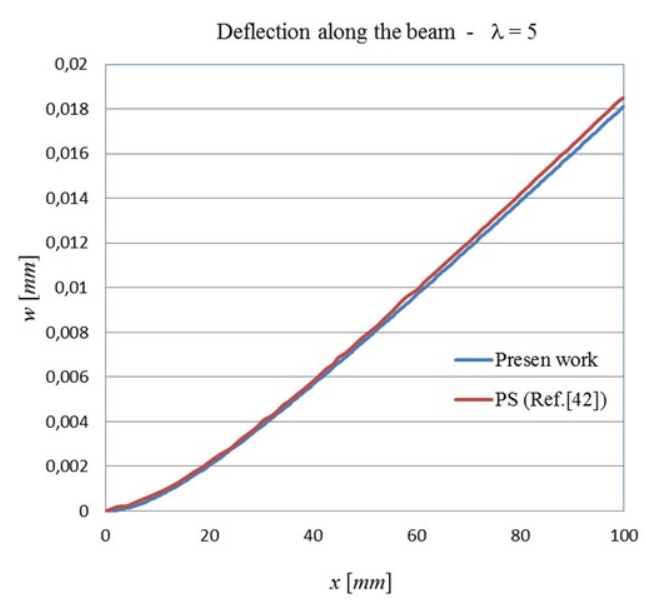

Fig. 8 Transverse deflection of non-symmetric (composite C) cantilever thick beam under end point load ( $\lambda=5$ ).
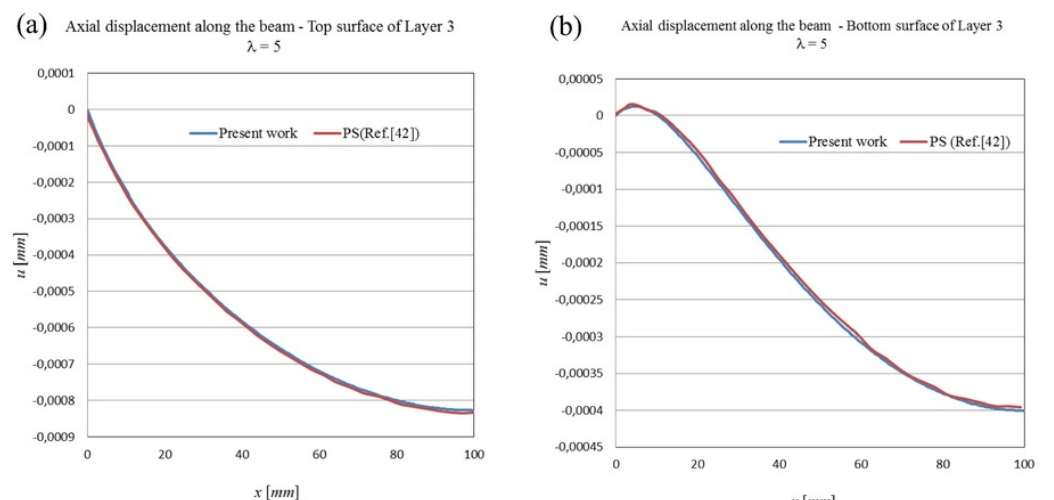

Fig. 9 Non symmetric (composite C) cantilever thick beam ( $\lambda=5$ ) under end point load. Axial displacements (a) at the upper surface and (b) at the lower surface of layer 3 (top layer). 

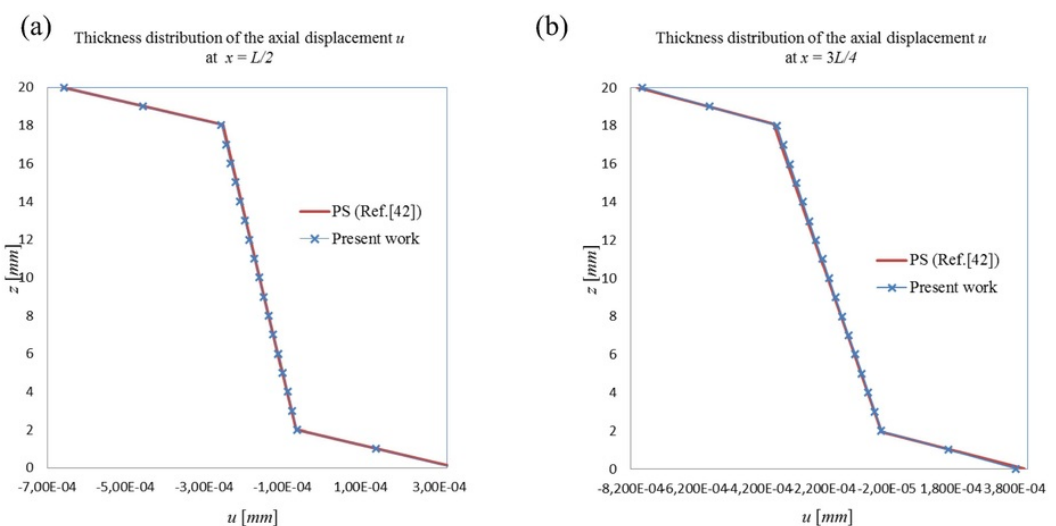

Fig. 10 Non symmetric (composite C) cantilever thick beam ( $\lambda=5$ ) under end point load. Thickness distribution of the axial displacement (a) at $x=L / 2$ and (b) at $x=3 L / 4$.

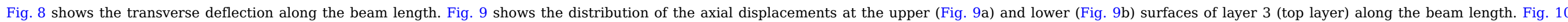

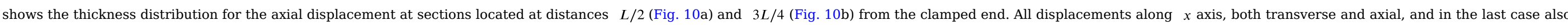

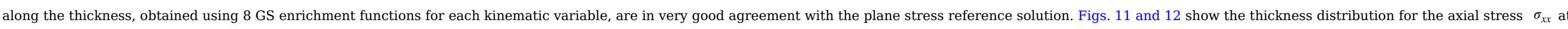

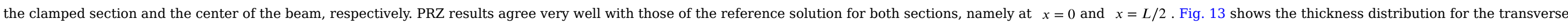

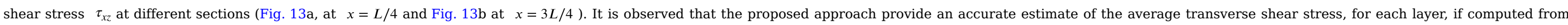

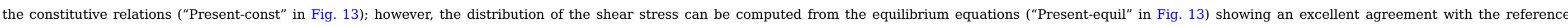
solution.

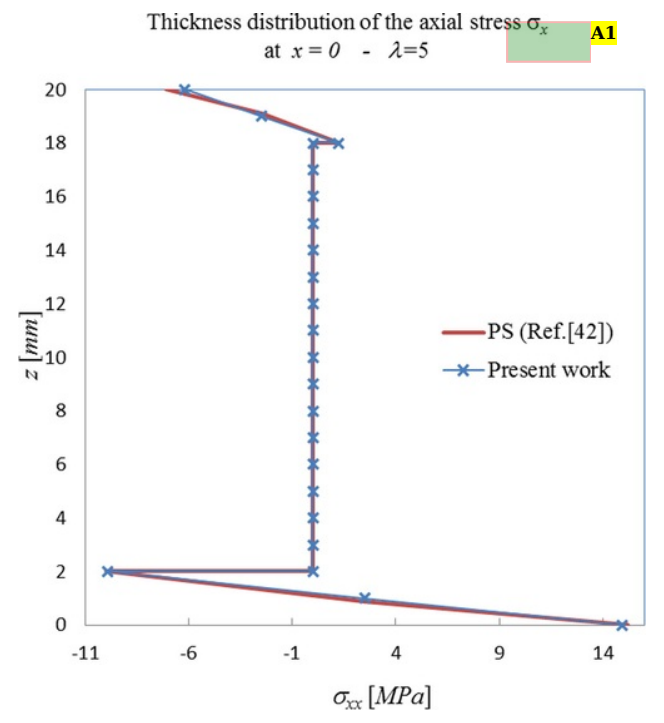

Fig. 11 Non symmetric (composite C) cantilever thick beam $(\lambda=5)$ under end point load. Thickness distribution of the axial stress $\sigma_{x x}$ at $x=0$.

Annotations:

A1. sigma $\mathrm{xx}$ (Please add another $\mathrm{x}$ as a subscript) 


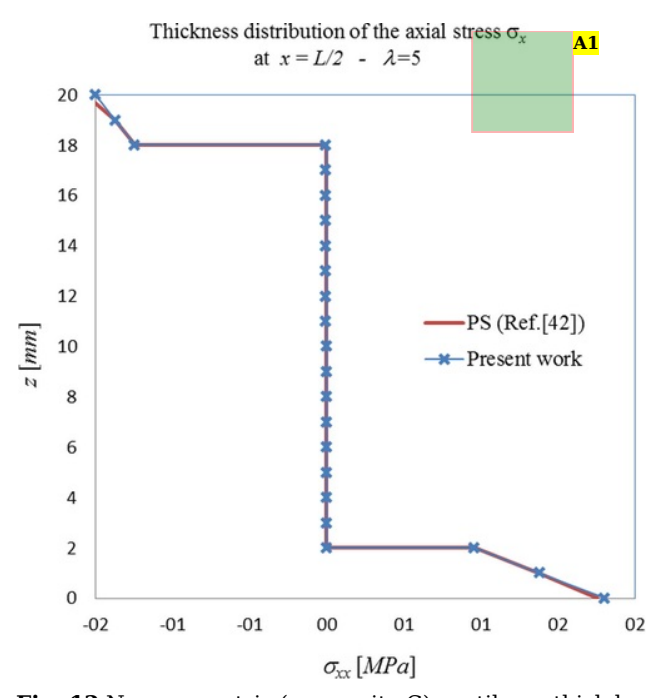

Fig. 12 Non symmetric (composite C) cantilever thick beam $(\lambda=5)$ under end point load. Thickness distribution of the axial stress $\sigma_{x x}$ at $x=L / 2$.

\section{Annotations:}

A1. sigma $x x$. Please add another $x$ as a subscript

(a) Thickness distribution of transverse shear stress $\tau_{\text {to }}$
at $x=L / 4-\lambda=5$

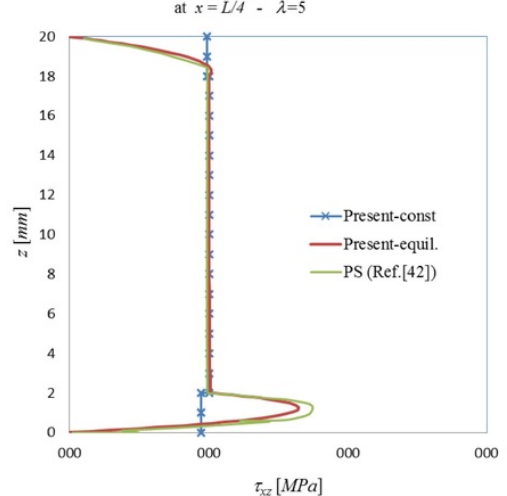

(b)

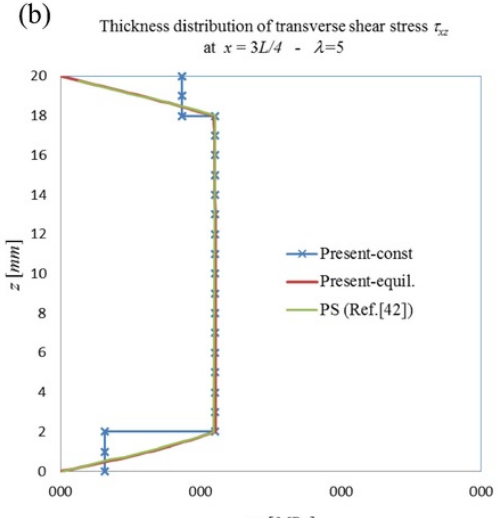

Fig. 13 Non symmetric (composite C) cantilever thick beam $(\lambda=5)$ under end point load. Thickness distribution of transverse shear stress $\tau_{x z}$ at a) $x=L / 4$ and b) $x=3 L / 4$.

\subsection{Three-layered simple supported thick beam under uniform load}

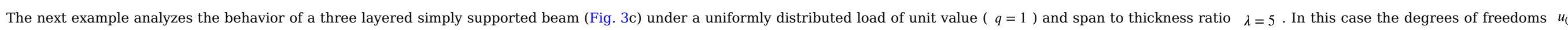
and $w$ are restrained at both beam ends $(x=0, L)$, unlike the beam shown in Fig. $3 \mathrm{~b}$.

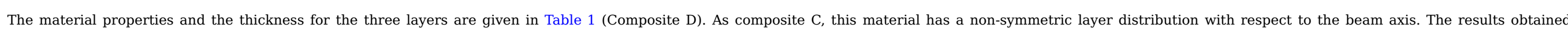

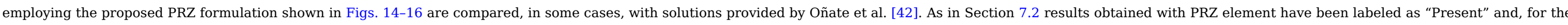

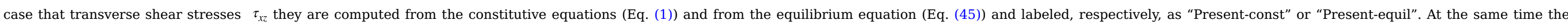
reference values are labeled as "PS" for results from plane stress and "RI" for results using two-noded linear beam element with reduced integration. 


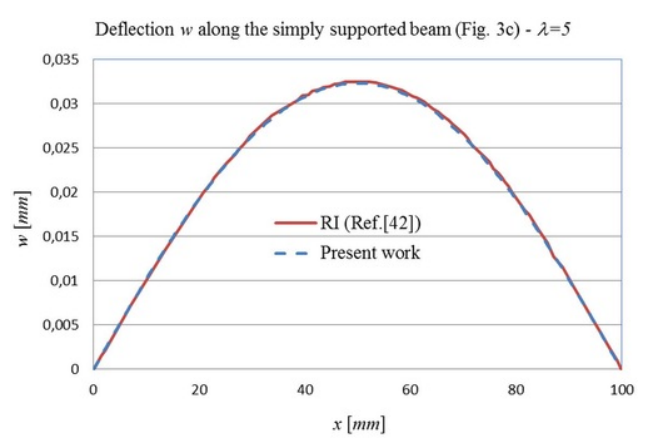

Fig. 14 Simply supported non-symmetric laminated (Composite D) thick beam. Vertical deflection $w$ along the beam length.
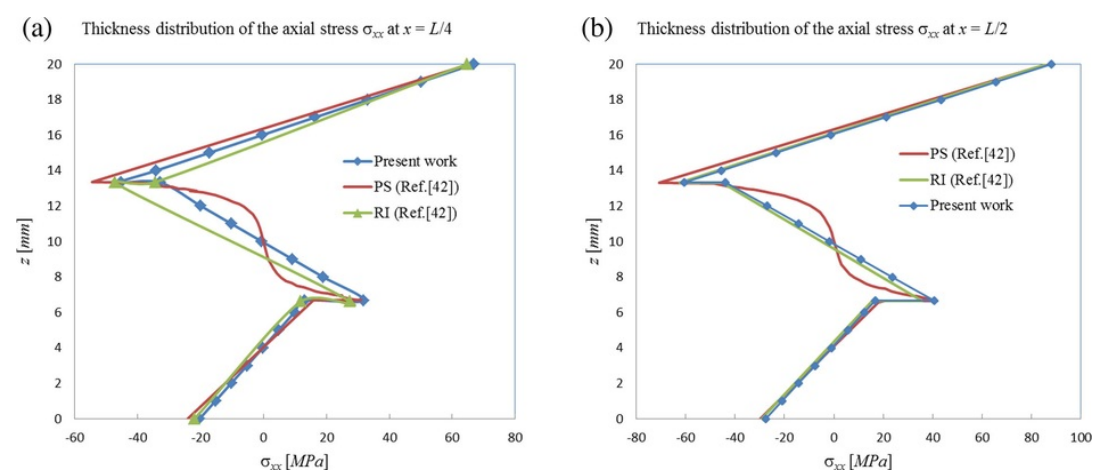

Fig. 15 Simply supported thick beam (Composite D) $\lambda=5$. Thickness distribution of axial stress $\sigma_{x x}$ at a) $x=L / 4$ and b) $x=L / 2$.
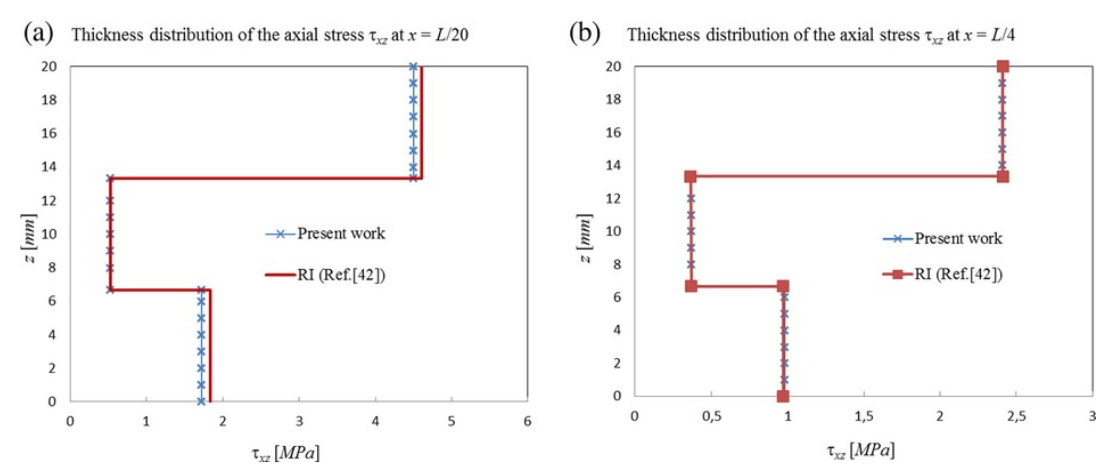

Fig. 16 Simply supported thick beam (Composite D) $\lambda=5$. Thickness distribution of transverse shear stress $\tau_{x z}$ at a) $x=L / 20$ and b) $x=L / 4$.

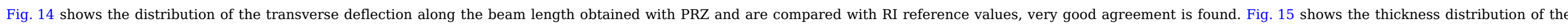

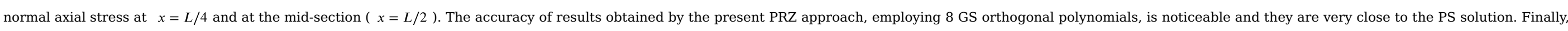

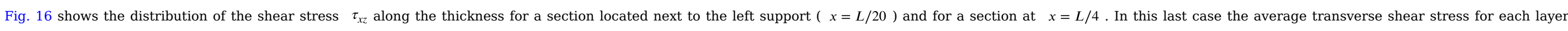
(obtained from the constitutive equation) are compared with RI results, showing a very good agreement.

\section{Modeling of delamination with the PRZ element}

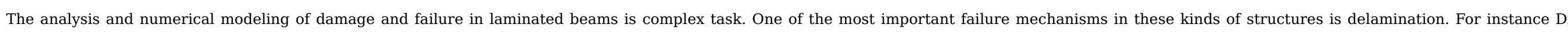




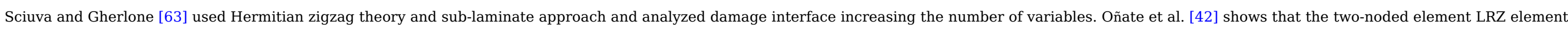

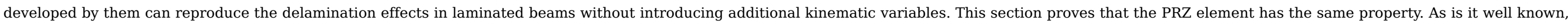

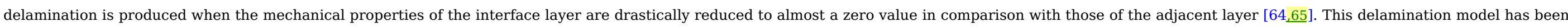

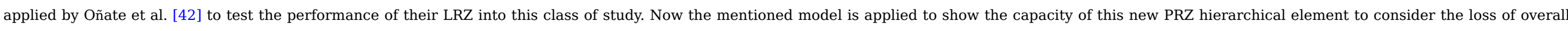
rigidity of the beam due to delamination, leading to an increase in displacement field components.

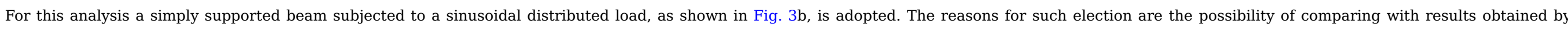

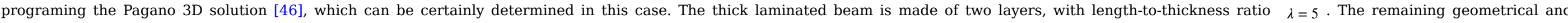

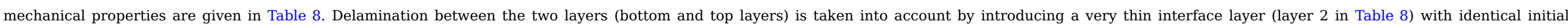
properties to the top layer. Next, the transverse shear modulus of the interface layer $\left(G_{2}\right)$ is progressively reduced from Model 1 to Model 12 as shown in Table 9.

Table 8 Thickness and layer properties for delamination study in a 2-layered beam. G2 values are depicted in Table 9.

\begin{tabular}{|c|c|c|c|}
\hline & Layer 1 (bottom) & Layer 2 & Layer 3 (top) \\
\hline$h[\mathrm{~mm}]$ & 14 & 0.01 & 6 \\
\hline$E[\mathrm{Mpa}]$ & $0.073 E+05$ & $2.19 \mathrm{E}+05$ & $2.19 \mathrm{E}+05$ \\
\hline G[Mpa] & $0.029 \mathrm{E}+05$ & Model & $8.76 \mathrm{E}+04$ \\
\hline
\end{tabular}

Table 9 Shear modulus $G_{2}$ in MPa, for the interface layer for delamination analysis.

\begin{tabular}{|c|c|c|c|c|c|}
\hline Model & $G_{2}$ & Model & $G_{2}$ & Model & $G_{2}$ \\
\hline 1 & $8.76 \mathrm{E}+004$ & 5 & $8.76 \mathrm{E}+000$ & 9 & $8.76 \mathrm{E}-004$ \\
\hline 2 & $8.76 \mathrm{E}+003$ & 6 & $8.76 \mathrm{E}-001$ & 10 & $8.76 \mathrm{E}-005$ \\
\hline 3 & $8.76 \mathrm{E}+002$ & 7 & $8.76 \mathrm{E}-002$ & 11 & $8.76 \mathrm{E}-006$ \\
\hline 4 & $8.76 \mathrm{E}+001$ & 8 & $8.76 E-003$ & 12 & $8.76 \mathrm{E}-007$ \\
\hline
\end{tabular}

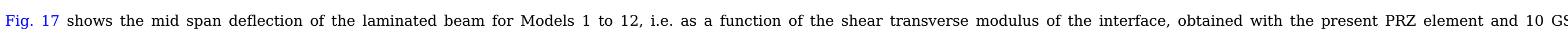

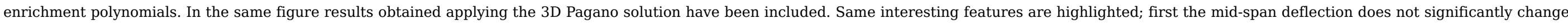

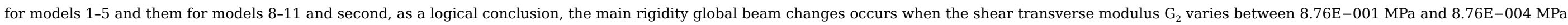

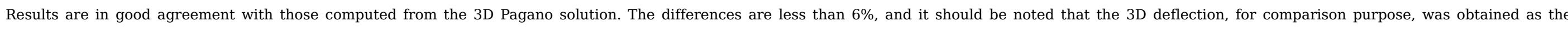
weighted deflection in the thickness beam at $x=L / 2$. 


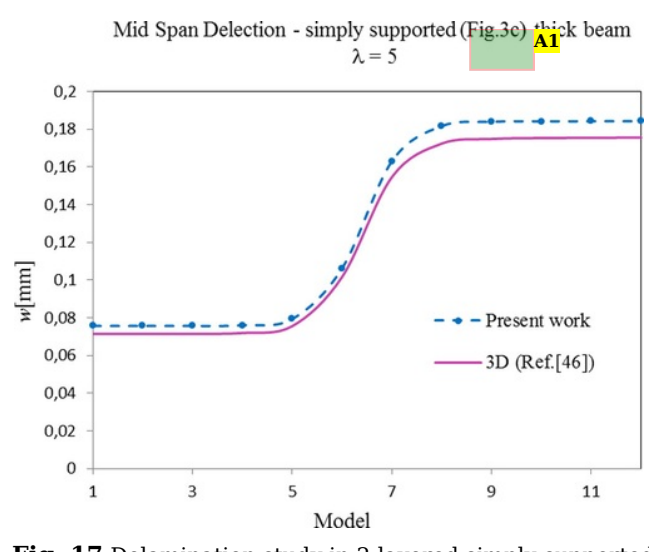

Fig. 17 Delamination study in 2-layered simply-supported thick beam under sinusoidal load. Evolution of mid span transverse deflection with shear modulus $\mathrm{G}_{2}$ according to Table 9.

\section{Annotations:}

A1. Must be Fig. 3b instead of Fig. 3c

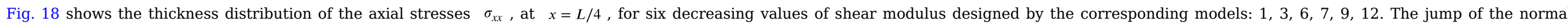

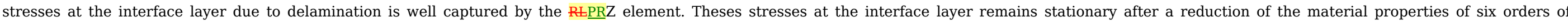
magnitude. It is important to note the excellent concordance with the 3D solution that has been obtained applying the Pagano solution [46].

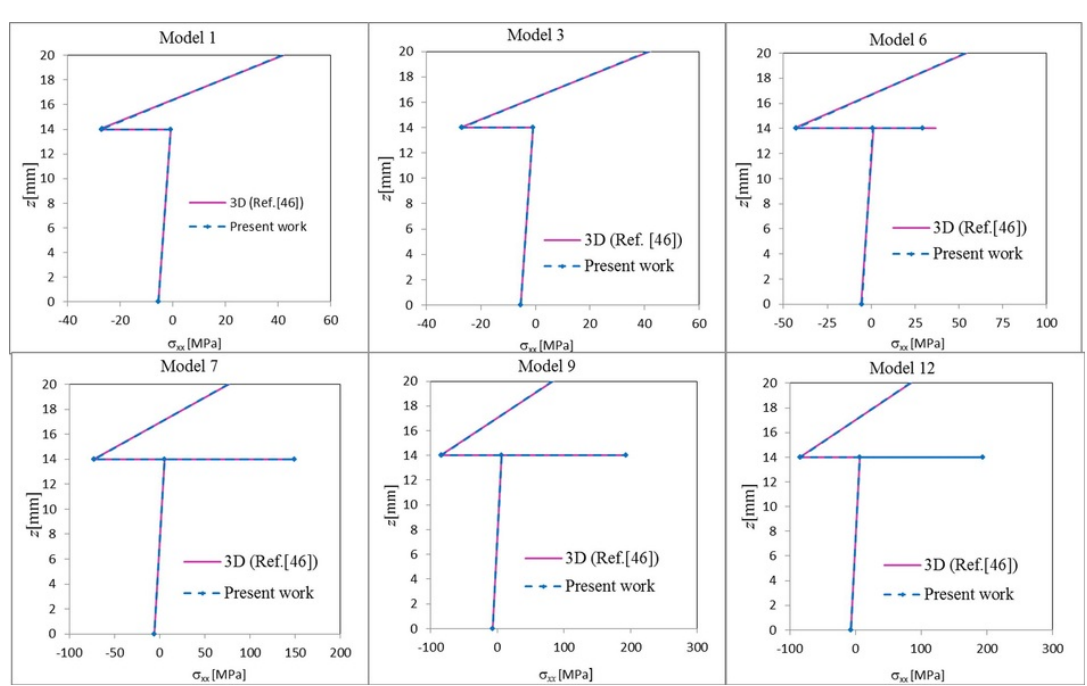

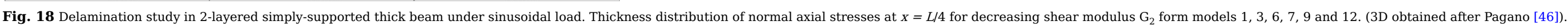

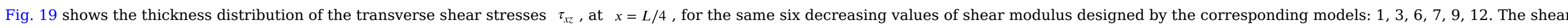

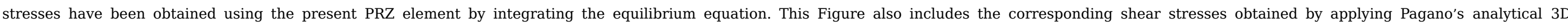
formulation. Note again the noticeable agreement between the two solutions. Once again the accuracy of PRZ element to capture the delamination effects is demonstrated. 


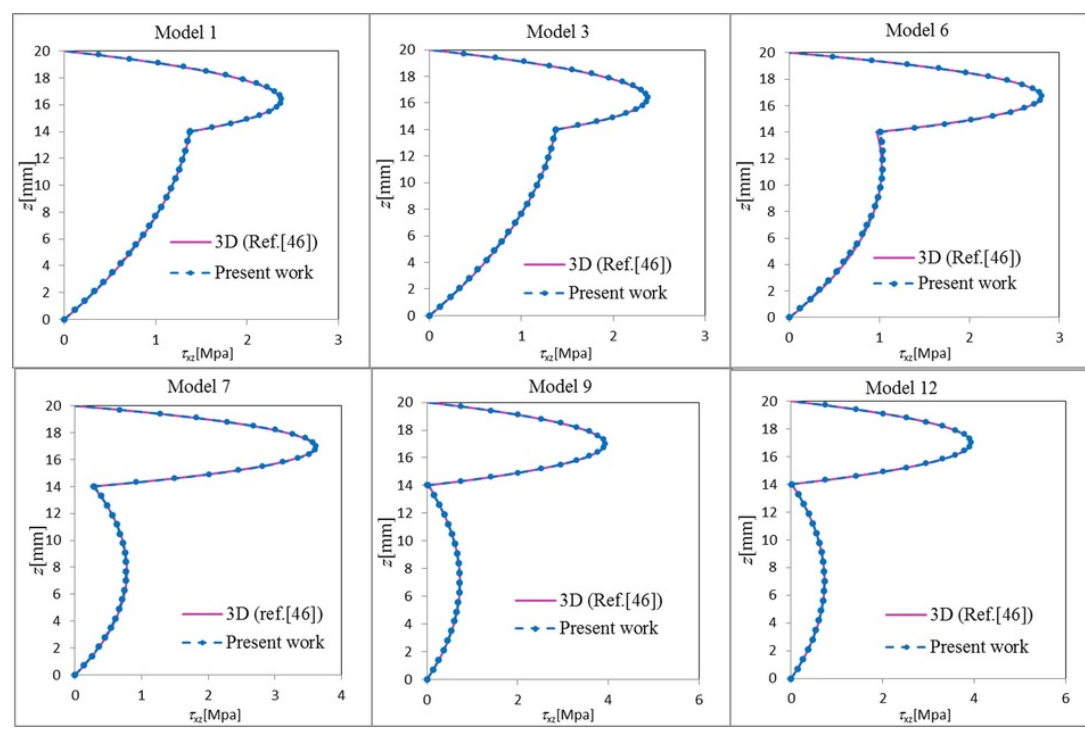

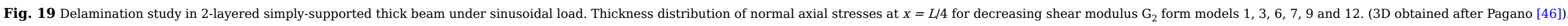

\section{Conclusions}

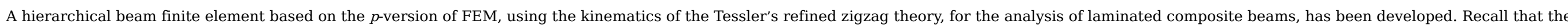

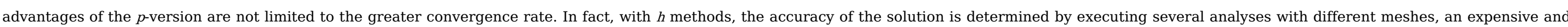

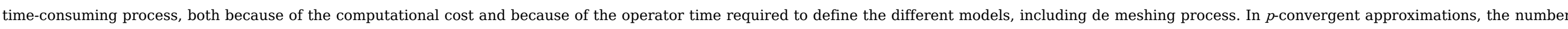

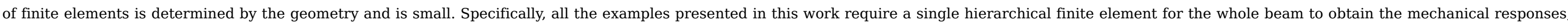

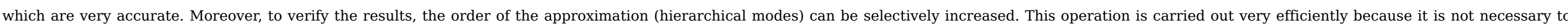

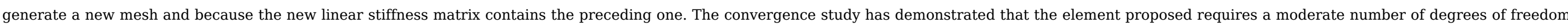

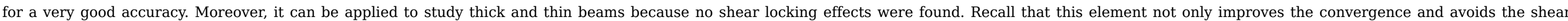

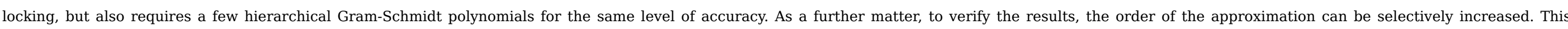

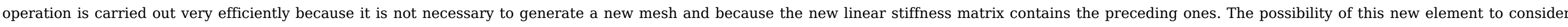

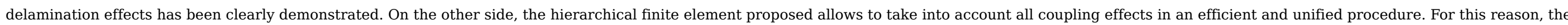
developed PRZ element can be applied to the analysis of laminated beam with functionally graded materials or damage profile at laminar levels, and it is currently studied by the authors.

\section{References}

[1] E. Carrera, Historical review of zig-zag theories for multilayered plates and shells, Appl Mech Rev 56, 2003, 65-75.

[2] E. Carrera, Theories and finite elements for multilayered, anisotropic, composite plates and shells, Arch Comput Methods Eng 9, 2002 , 87-140.

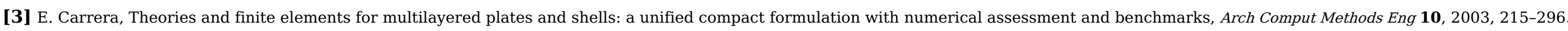

[4] L. Demasi, $\infty 6$ Mixed plate theories based on the generalized unified formulation. Part I: Governing equations, Compos Struct 87, 2009, 1-11.

[5] L. Demasi, $\infty 6$ Mixed plate theories based on the generalized unified formulation. Part II: layerwise theories, Compos Struct 87, $2009,12-22$.

[6] L. Demasi, $\infty 6$ Mixed plate theories based on the generalized unified formulation. Part III: advanced mixed high order shear deformation theories, Compos Struct 87, 2009, 183-194. 
[7] L. Demasi, $\infty 6$ Mixed plate theories based on the generalized unified formulation. Part IV: zig-zag theories, Compos Struct 87, 2009, 195-205.

[8] L. Demasi, $\infty 6$ Mixed plate theories based on the generalized unified formulation. Part V: results, Compos Struct 88, 2009, 1-16.

[9] S. Timoshenko, Theory of elasticity, 1934, McGraw-Hill Book Company Inc; New York

[10] F.P. Pai, A new look at shear correction factors and warping functions of anisotropic laminates, IntJ Solids Struct 32, 1995, $2295-2313$.

[11] J.N. Reddy, A simple higher - order theory for laminated composite plates, J Appl Mech. Trans ASME 51 (4), 1984, 745-752.

[12] A.V.K. Murty, Toward a consistent beam theory, AIAAJ 22 (6), 1984, 811-816.

[13] K. Surana and S. Nguyen, Two-dimensional curved beam element with higher order hierarchical transverse approximation for laminated composites, Comput Struct 36, 1990, 499-511.

[14] H. Matsunaga, Vibration and buckling of multilayered composite beams according to higher order deformation theories, J Sound Vib 246 (1), 2001 , 47-62.

[15] M. Touratier, An efficient standard plate theory, Int J Eng SCi 19 (8), 1991, 745-752.

[16] M. Touratier, A refined theory of laminated shallow shells, Int J Solids Struct 29 (11), 1992, 1401-1415.

[17] A.J.M. Ferreira, C.M.C. Roque and R.M.N. Jorge, Analysis of composite plates by trigonometric shear deformation theory and multiquadrics, Comput Struct 83 (27), 2005, 2225-2237.

[18] P. Vidal and O. Polit, A family of sinus finite elements for the analysis of rectangular laminated beams, Compos Struct 84 (1), $2008,56-72$.

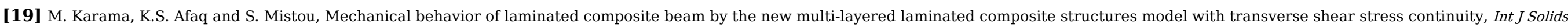
Struct 40 (6), 2003, 1525-1546.

[20] M. Aydogdu, A new shear deformation theory for laminated composite plates, Compos Struct 89 (1), 2009, 94-101.

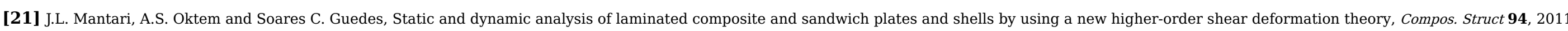
37-49.

[22] K.P. Soldatos, A transverse shear deformation theory for homogenous monoclinc plates, Acta Mech. 94, 1992, 195-220.

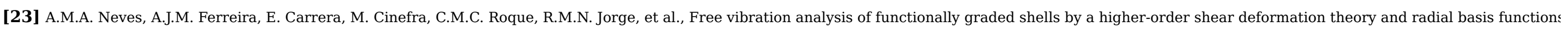
collocation, accounting for through-the-thickness deformations, EurJ Mech A Solids 37, 2013, 24-34.

[24] E. Carrera, M. Filippi and E. Zappino, Laminated beam analysis by polinomial, trigonometric, exponential and zig-zag theories, Euro J Mech A/Solids 41, 2013 , 58-59.

[25] P. Vidal, L. Gallimard and O. Polit, Composite beam finite element based on the proper generalized decomposition, Comput Struct 102-103, 2012, 76-86.

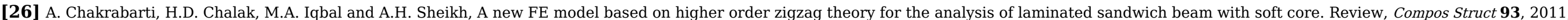
271-279.

[27] D.H.J. Robbins and J.N. Reddy, Modeling of thick composites using a layer-wise theory, Int J Numer Methods Eng 36, 1993 , 655-677.

[28] S. Srinivas, A refined analysis of composite laminates, J Sound Vib 30, 1973, 495-507.

[29] J.N. Reddy, Generalization of two-dimensional theories of laminated composite plates, Commun Appl Numer Methods 3, 1987, 173-180.

[30] A. Toledano and H. Murakami, A composite plate theory for arbitrary laminate configuration, J Appl Mech 54, 1987, 181-189.

[31] X. Lu and D. Liu, An interlaminar shear stress continuity theory for both thin and thick composite laminates, J Appl Mech 59, $1992,502-509$. 
[32] C.Y. Lee and D. Liu, An interlaminar stress continuity theory for laminated composite analysis, Comput Struct 42, 1992, 69-78.

[33] P. Pai and A. Palazotto, A higher-order sandwich plate theory accounting for a 3-d stresses, Int J Solids Struct 38, 2001, 5045-5062.

[34] A. Ferreira, Analysis of composite plates using a layerwise shear deformation theory and multiquadrics discretization, Mech Adv Mater Struct 12, 2005 , 99-112.

[35] H. Murakami, Laminated composite plate theory with improved in-plane responses, J Appl Mech 53, 1986, 661-666.

[36] S.P. Lee, N.R. Senthilnathan, S.P. Lim and S.T. Chow, An improved zigzag model for the bending of laminated composite plates, Compos Struct 15, 1990, 137-148.

[37] M. Cho and R.R. Parmerter, Efficient higher order composite plate theory for general lamination configurations, AIAA J 31 (7), 1993, 1299-1306.

[38] Y.B. Cho and R.C. Averill, An improved theory and finite element model for laminated beams using first order zigzag sub-laminate approximations, Compos Struct 37, 1997, 281-298.

[39] P. Vidal and O. Polit, Assessment of the refined sinus model for the non-linear analysis of composite beams, Compos Struct 87, 2009, 370-381.

[40] P. Vidal and O. Polit, A sine finite element using a zig-zag function for the analysis of laminated composite beams, Compos: Part B 42, 2011 , $1671-1682$.

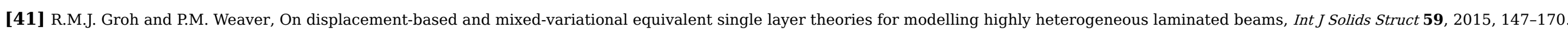

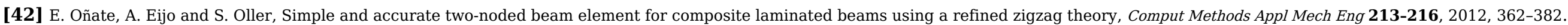

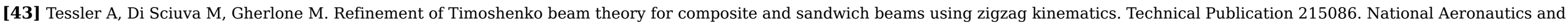
Space Administration; 2007

[44] A. Tessler, M. Di Sciuva and M. Gherlone, A refined zig-zag beam theory for composite and sandwich beams, J Compos Mater 43 (9), $2009,1051-1081$.

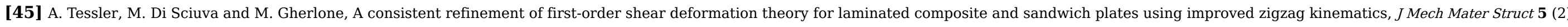
2010, 341-367.

[46] N. Pagano, Exact solutions for rectangular bidirectional composites and sandwich plates, J Compos Mater 4, 1970, $20-34$.

[47] G. Daví, A. Milazzo and C. Orlando, An analytical solution for multilayered beams subjected to ends loads, Compos Struct 116, $2014,772-781$.

[48] O.C. Zienkiewicz and R.L. Taylor, The finite element method, 4th ed, 1988, McGraw-Hill; London.

[49] B. Szabó, A. Düster and E. Rank, The p-version of the finite element method. encyclopedia of computational mechanics, 2004, Wiley Online Library.

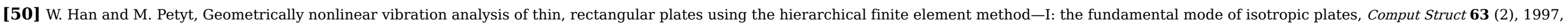
295-308.

[51] P. Ribeiro and M. Petyt, Multi-modal geometrical non-linear free vibration of fully clamped composite laminated plates, J Sound Vib 225 (1), $1999,127-152$.

[52] P. Ribeiro and M. Petyt, Nonlinear vibration of composite laminated plates by the hierarchical finite element and continuation methods, Compos Struct 46 (3), 1999 , $197-208$.

[53] B.A. Szabó and A.K. Mehta, P-convergent finite element approximations in fracture mechanics, Int J Numer Meth Eng 12 (3), $1978,551-560$.

[54] B.A. Szabó and I. Babuska, Finite element analysis, 1991, Wiley; New York.

[55] P. Ribeiro, First-order shear deformation, p-version, finite element for laminated plate nonlinear vibrations, AIAAJ 43 (6), 2005, 1371-1379.

[56] R.M. Jones, Mechanics of composite materials, 2nd ed, 2015, CRC Press.

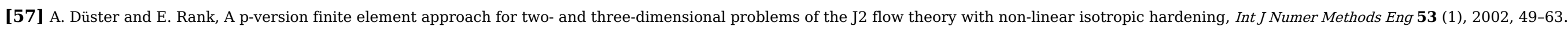




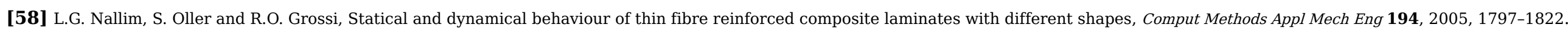

[59] L.G. Nallim and S. Oller, An analytical - numerical approach to simulate the dynamic behaviour of arbitrarily laminated composite plate, Compos Struct J 85, 2008 , 311-325.

[60] R.F. Rango, L.G. Nallim and S. Oller, Static and dynamic analysis of thick laminated plates using enriched macroelements, Compos Struct J 101, 2013, 94-103.

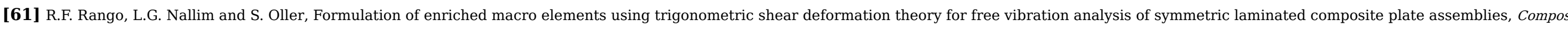
Struct J 119, 2015, 38-49.

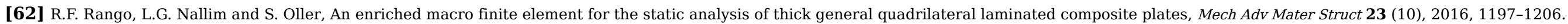

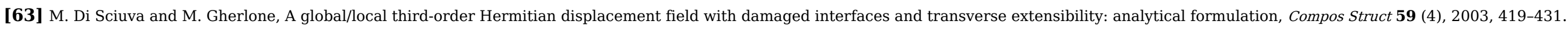

[64] S. Oller, Numerical simulation of mechanical behavior of composite materials, 2015, Springer; Barcelona noded zigzag beam element accounting for shear effects based on an extended Euler Bernoulli theory. Composite Structures 2015;132(15):1192-1205.

\section{Queries and Answers}

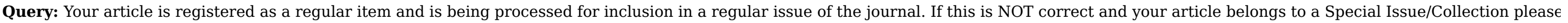
contact s.priya.1@elsevier.com immediately prior to returning your corrections.

Answer: Ok

Query: The author names have been tagged as given names and surnames (surnames are highlighted in teal color). Please confirm if they have been identified correctly.

Answer: Ok

Query: The affiliations "a and b" has been split into two different affiliations. Please check, and correct if necessary.

Answer: I corrected the affiliations

Query: Please check the address for the corresponding author that has been added here, and correct if necessary.

Answer: corrected 